\title{
Regression curves for vibration transmission across junctions of heavyweight walls and floors based on finite element methods and wave theory
}

\author{
C. Hopkins ${ }^{* 1}$, Ch. Crispin ${ }^{\dagger 2}$, J. Poblet-Puig ${ }^{\ddagger 3}$ and J. Guigou-Carter ${ }^{\S 4}$ \\ ${ }^{1}$ Acoustics Research Unit, School of Architecture, University of \\ Liverpool \\ ${ }^{2}$ Belgian Building Research Institute - Acoustics Division \\ ${ }^{3}$ Laboratori de Càlcul Numèric, E.T.S. d'Enginyers de Camins, Canals \\ i Ports de Barcelona, Universitat Politècnica de Catalunya \\ ${ }^{4}$ Centre Scientifique et Technique du Bâtiment
}

August 10, 2016

\begin{abstract}
Sound insulation prediction models in European and International standards use the vibration reduction index to calculate flanking transmission across junctions of walls and floors. These standards contain empirical relationships between the ratio of mass per unit areas for the walls/floors that form the junction and a frequency-independent vibration reduction index. Calculations using wave theory show that there is a stronger relationship between the ratio of characteristic moment impedances and the transmission loss from which the vibration reduction index can subsequently be calculated. In addition, the assumption of frequency-independent vibration reduction indices has been shown to be incorrect due to in-plane wave generation at the junction. Therefore numerical experiments with FEM, SFEM and wave theory have been used to develop new regression curves between these variables for the low-, mid- and high-frequency ranges. The junctions considered were L-, T- and X-junctions formed from heavyweight walls and floors. These new relationships have been implemented in the prediction models and they tend to improve the agreement between the measured and predicted airborne and impact sound insulation.
\end{abstract}

*correspondence: Liverpool L69 7ZN, United Kingdom, e-mail: carl.hopkins@liverpool.ac.uk

${ }^{\dagger}$ correspondence: Lombardstraat 42 B-1000 Brussels, Belgium, e-mail: charlotte.crispin@bbri.be

${ }^{\ddagger}$ correspondence: UPC, Campus Nord B1, Jordi Girona 1, E-08034 Barcelona, Spain, e-mail: jordi.poblet@upc.edu

${ }^{\S}$ correspondence: 24 rue Joseph Fourier, 38400 Saint Martin d'Hères, France, e-mail: catherine.guigou@cstb.fr 


\section{Introduction}

Prediction of airborne and impact sound insulation in heavyweight buildings requires consideration of both direct and flanking transmission because the latter is often critical in determining the in situ sound insulation [1]. The International Standards, ISO 15712 Parts 1 and 2 [2] and the identical European Standards, EN 12354 Parts 1 and 2 [3] describe a prediction model to estimate the airborne and impact sound insulation based on the approach from Gerretsen [4]. This model considers transmission paths with vibration transmission across one junction of walls and/or floors using a parameter called the vibration reduction index, $K_{i j}$ [5]. Part 1 of these Standards has an informative annex (Annex E) which contains empirical relationships between $K_{i j}$ and the ratio of mass per unit areas for the walls and floors that form the junction.

Problems concerning the application of these empirical relationships have been discussed in detail by Hopkins [6]. These occur because the relationships were derived from a mixture of theoretical $K_{i j}$ values for isolated junctions and in situ measurements of $K_{i j}$ in real buildings. The latter contain unwanted flanking transmission from high-order flanking paths [7], whereas the prediction model only considers firstorder flanking paths. This conflicts with the approach prescribed in ISO 10848-1 [8] to provide data for the prediction model by measuring $K_{i j}$ on isolated junctions in the laboratory (i.e. without high-order flanking paths). Laboratory measurements on isolated heavyweight junctions with rigid connections have shown varying degrees of agreement with the empirical relationships (e.g. see $[9,10])$. One reason for this is that it has been shown that $K_{i j}$ measurements on heavyweight junctions in both the laboratory and the field will often incur significant errors due to unwanted flanking transmission [7]. Some calculations of airborne and impact sound insulation using the empirical relationships have shown reasonable agreement with existing field sound insulation databases for heavyweight buildings (e.g. see [4, 11]). However, it has also been shown that bias errors up to $+10 \mathrm{~dB}$ occur in the airborne sound insulation when compared with matrix SEA which considers all possible transmission paths $[1,12,13]$. Comparisons of measured and predicted single-number quantities for airborne and impact sound insulation do not always show these bias errors (e.g. see [4]). This could be attributed to the fact that single-number quantities often obscure discrepancies in the frequency trends of the sound insulation curves with emphasis on the low- and mid-frequency ranges. Some comparisons do indicate a bias error but this could also be attributed to the input data [14].

To assess the empirical relationships in this informative annex of the European and International Standards, Hopkins [6] used wave theory to calculate the vibration reduction index for L-, T- and X-junctions of solid masonry/concrete walls and floors. A theoretical approach was used because of the problems inherent in $K_{i j}$ measurements with heavyweight junctions [7]. Calculations were carried out assuming only bending wave transmission at the junction, as well as bending and in-plane wave transmission at the junction. For typical heavyweight walls and floors in the low-frequency range, only bending wave transmission is relevant which gives a frequency-invariant $K_{i j}$. However, it was shown that the frequency-invariant empirical $K_{i j}$ data in the European and International Standards were likely to give rise to errors in the midand high-frequency ranges due to the importance of in-plane wave generation at the 
junction. Regression analysis with the wave theory data was used to identify new relationships between $K_{i j}$ and the ratio of mass per unit areas for the walls/floors forming the junction. The results indicated that it was feasible to generate new empirical curves for (a) the low-frequency range $(50 \mathrm{~Hz}$ to $200 \mathrm{~Hz})$ using bending wave theory and (b) the mid-frequency range $(250 \mathrm{~Hz}$ to $1 \mathrm{kHz})$ and high-frequency range $(1.25 \mathrm{kHz}$ to $5 \mathrm{kHz})$ using bending and in-plane wave theory.

Based on laboratory measurements of the vibration reduction index, Crispin and Ingelaere [15] noted that the ratio of mass per unit areas might not be the optimal parameter to establish empirical relationships for $K_{i j}$. In their seminal work on structure-borne sound, Cremer et al [16] identified the ratio of characteristic moment impedances as the independent variable that described the bending wave transmission loss across L-, T- and X-junctions. Crispin et al [17] proposed that this ratio of characteristic moment impedances would be a more suitable independent variable than a ratio of mass per unit areas when establishing empirical relationships for $K_{i j}$. This was assessed by using Finite Element Methods (FEM) with T- and X-junctions to calculate $K_{i j}$ as a single frequency-average value between $200 \mathrm{~Hz}$ and $1.25 \mathrm{kHz}$. These results indicated that $K_{i j}$ data tend to cluster more closely together when using the ratio of characteristic moment impedances rather than the ratio of mass per unit areas. Subsequent numerical experiments by Poblet-Puig and Guigou-Carter [18] used the spectral element method to investigate junctions of solid masonry/concrete walls and floors which opened up the possibility of much faster and efficient calculations than traditional FEM. These numerical simulations also resulted in frequency-dependent $K_{i j}$ as was observed with wave theory [6] for which average results were presented in the low-, mid- and high-frequency ranges.

The revision of ISO 15712 and EN12354 led by CEN TC126 WG2 (Chairman: Michel Villot) began in 2013, and at the meeting in 2014 the working group proposed that based on their recent research, the authors of the present paper should collaborate to use prediction models to produce new $K_{i j}$ relationships for the informative annex. This gave the authors an opportunity to consider whether it might be advantageous to determine relationships between transmission loss (rather than $K_{i j}$ ) and the ratio of characteristic moment impedances, from which $K_{i j}$ could subsequently be calculated. There was an additional impetus to introduce relationships for $K_{i j}$ that were relevant to the low-frequency range (particularly below $100 \mathrm{~Hz}$ ) because of recent changes to European and International standards on field sound insulation measurement which introduced a new low-frequency procedure in order to allow more repeatable and reproducible measurements [19].

In this paper, numerical experiments with FEM, Spectral Finite Element Methods (SFEM) and wave theory were used to (a) optimise the choice of variables to determine $K_{i j}$ where the prime candidate for the independent variable is the ratio of characteristic moment impedances, and (b) develop new relationships to determine $K_{i j}$ for the low-, mid- and high frequency ranges. The focus was on solid, heavyweight walls and floors which were rigidly connected to form L-, T- and X-junctions (see Fig. 1). FEM and SFEM calculations were able to account for the finite size of typical walls and floors and captured modal features of $K_{i j}$, particularly in the low-frequency range. However, the FEM and SFEM results were specific to the damping that was assumed for the plates in the FEM or SFEM model [18]. Diffuse field wave theory was used 
to calculate the diffuse field transmission loss for junctions of semi-infinite plates and gives a generic result which is independent of wall and floor dimensions and damping. This approach not only applies to walls and floors with diffuse vibration fields, but it has been shown that it gives a reasonable estimate for the average of many junctions of heavyweight walls and floors with low mode counts and low modal overlap [20]. The final stage was to assess the implications of using the new $K_{i j}$ relationships when estimating the sound insulation by inserting them in the prediction model in the European and International Standards.

(a)

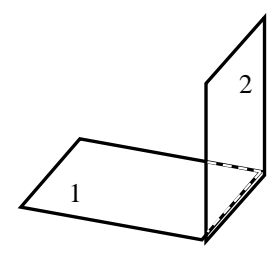

(b)

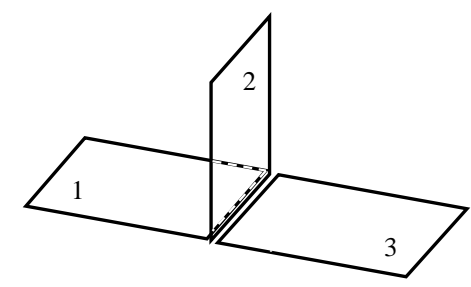

(c)

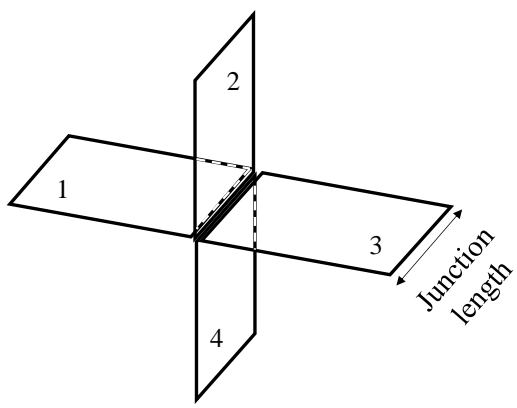

Figure 1: Junction types: (a) L-junction, (b) T-junction (c) X-junction.

\section{Methodology}

Numerical experiments were used with FEM, SFEM and wave theory to determine the vibration reduction index which is defined as $[2,3]$

$$
K_{i j}=\overline{D_{\nu, i j}}+10 \log _{10}\left(\frac{\ell_{i j}}{\sqrt{a_{i} a_{j}}}\right)
$$

where $\ell_{i j}$ is the junction length between elements $i$ and $j$, a is the equivalent absorption length and $\overline{D_{\nu, i j}}$ is the direction-averaged velocity level difference given by

$$
\overline{D_{\nu, i j}}=\frac{D_{\nu, i j}+D_{\nu, j i}}{2}
$$

in which $D_{\nu, i j}$ is the velocity level difference between source element $i$ and receiver element $j$ (and vice versa for $D_{\nu, j i}$ ). The equivalent absorption length is given by

$$
a_{i}=\frac{2.2 \pi S_{i}}{c T_{i}} \sqrt{\frac{f_{r e f}}{f}}=\frac{\pi S_{i} \eta}{c} \sqrt{f_{r e f} f}
$$


where $S$ is the area, $c$ is the speed of sound in air, $T_{i}$ is the structural reverberation time, $f_{r e f}$ is a reference frequency of $1000 \mathrm{~Hz}, f$ is the frequency, and $\eta$ is the total loss factor.

The angular-average transmission coefficient, $\gamma_{i j}$, for bending wave transmission from plate $i$ to plate $j$ is related to the vibration reduction index by

$$
-10 \log _{10}\left(\gamma_{i j}\right)=K_{i j}-5 \log _{10}\left(\frac{f_{c, j}}{f_{r e f}}\right)
$$

where $-10 \log _{10}\left(\gamma_{i j}\right)$ is referred to as the transmission loss in decibels.

FEM and SFEM models are described in Section 2.1 and wave theory modelling in Section 2.2. FEM and SFEM were used to determine $K_{i j}$ with Eq. (1) from which $\gamma_{i j}$ can be calculated with Eq. (4) whereas wave theory was used to directly determine

$\gamma_{i j}$ from which $K_{i j}$ can be calculated with Eq. (4). The numerical experiments use a Monte Carlo approach to represent a range of realistic junctions with heavyweight walls and floors of different sizes that are formed from different materials as described in Section 2.3.

Numerical experiments were carried out over the building acoustics frequency range. For sound insulation in buildings, many general trends can be described by defining the low-, mid-, and high-frequency ranges in one-third octave bands where the low-frequency range is $50 \mathrm{~Hz}$ to $200 \mathrm{~Hz}$, the mid-frequency range is $250 \mathrm{~Hz}$ to 1 $\mathrm{kHz}$, and the high-frequency range is $1.25 \mathrm{kHz}$ to $5 \mathrm{kHz}$ [1]. Whilst the aim was to introduce new $K_{i j}$ relationships that apply to the $50 \mathrm{~Hz}, 63 \mathrm{~Hz}$ and $80 \mathrm{~Hz}$ one-third octave bands, previous work (e.g. see $[1,6,18]$ ) indicates that there is no advantage in considering these frequency bands separately to the bands between $100 \mathrm{~Hz}$ and 200 $\mathrm{Hz}$.

\subsection{Finite element modelling with FEM and SFEM}

Two different types of finite element calculations were used: FEM and SFEM. For FEM calculations, the commercial software Actran (Version 15.1) used polynomial interpolation of the displacement field [21] whereas in SFEM the interpolation was carried out using the fundamental solutions of the shell equations [18]. Actran used a thin shell element (DSHELL) with the MUMPS solver [21] and SFEM used thin shell theory which was implemented as described by Poblet-Puig and Guigou-Carter [18].

Validations against measurements on junctions of heavyweight walls and floors have previously been carried out for both FEM [17, 18, 22, 23] and SFEM [18]. This led to the adoption of pinned junction lines for the low-frequency range and unpinned junction lines (i.e. no constraints on the junction nodes) for the mid- and highfrequency ranges. Typically there are no in-plane modes in the low-frequency range; hence a pinned junction only allows transmission of bending waves whereas in-plane modes occur in the mid- and high-frequency ranges and an unpinned junction allows generation of transverse shear and quasi-longitudinal waves. All other plate boundaries were pinned (i.e. displacement in the three coordinate directions was constrained but rotation was allowed) although in the SFEM model, the in-plane displacement in the junction direction was not constrained. 
At the outset of the research, additional checks were made between SFEM, Actran and another commercial finite element software, Ansys, which was used in previous work [1]. For a T-junction with pinned and unpinned junction conditions this indicated consistency in the general shape of the direction-average velocity level difference curves. However, the average difference between these three prediction models was 3.1 $\mathrm{dB}$ to $4.2 \mathrm{~dB}$ over the frequency range from $50 \mathrm{~Hz}$ to $3.15 \mathrm{kHz}$. This can be attributed to differences in the modelling such as the mesh, element type, excitation points, and post-processing. Mahn and Pearse [24] show that for this direction-average quantity, the uncertainty also depends on the difference between the directional velocity level differences. For these reasons the average difference would be expected to vary for different junctions. This justified the use of more than one type of finite element model for the research in this paper, because it was not possible to identify which model was the most accurate, or the most representative of all the different types of heavyweight walls and floors.

The frequency range covered by the calculations was one-third octave bands between $50 \mathrm{~Hz}$ and $3150 \mathrm{~Hz}$ using a logarithmic increment to give 5 or 6 frequencies in each band that were averaged to give a single value representing the band. This number of frequencies was a pragmatic choice to reduce computation times which had been validated in previous comparisons of FEM, SEA and measurements [1, 18, 22].

Excitation of bending waves on the source plate in a junction was applied using three non-correlated point forces in both Actran and SFEM. The source positions were chosen according to the criteria described in ISO 10848-1 [8] for laboratory measurements of $K_{i j}$.

The spatial-average velocity level was calculated using the finite element grid positions on each plate also determined following the requirements in ISO 10848-1 [8] on distance of sampling points from the excitation positions and boundaries. These were used to calculate velocity level differences in terms of Dv,ij for each junction from which $K_{i j}$ and $\gamma_{i j}$ were calculated according to Eqs. (1) and (4) respectively. The average mean-square vibration on each plate was determined using between $\approx 4000$ and $\approx 11000$ points with Actran, and $\approx 440$ points with SFEM.

\subsection{Wave theory}

Two wave theory models were used to calculate diffuse field transmission coefficients between semi-infinite plates, a bending wave only model for the low-frequency range and a bending and in-plane wave model (bending, transverse shear and quasilongitudinal waves) for the mid- and high-frequency ranges. The wave theory equations used for these calculations is described in [1]. The transmission coefficients from the bending only model are frequency-independent. However, the bending and in-plane model allows generation of in-plane waves at the junction which causes the transmission coefficients for bending wave transmission to vary with frequency. As there are rarely any in-plane modes in the low-frequency range, only the mid- and high-frequency ranges were considered for the bending and in-plane model for which a single value for the transmission loss was calculated from the arithmetic average of the values in those one-third octave bands. Thin plate bending theory was assumed and the diffuse field assumption was implemented using an angular resolution of $0.05^{\circ}$. 
Calculations were carried out at the one-third octave band centre frequencies between $50 \mathrm{~Hz}$ and $5 \mathrm{kHz}$.

\subsection{Heavyweight junctions used for the modelling with FEM, SFEM and wave theory}

Ensembles of L-, T- and X-junctions for the FEM and wave theory models were defined using the material properties given in Table 1 [6]. The plate thicknesses were $100 \mathrm{~mm}, 200 \mathrm{~mm}$ or $300 \mathrm{~mm}$.

\begin{tabular}{lcccc}
\hline Material & $\eta_{\text {int }}(-)$ & $\rho\left(\mathrm{kg} / \mathrm{m}^{3}\right)$ & $c_{L}(\mathrm{~m} / \mathrm{s})$ & $\nu(-)$ \\
\hline Concrete & 0.005 & 2200 & 3800 & 0.2 \\
Brick & 0.01 & 1750 & 2700 & 0.2 \\
Aerated concrete & 0.0125 & 800 & 1900 & 0.2 \\
Lightweight aggregate & 0.01 & 1400 & 1400 & 0.2 \\
Dense aggregate & 0.01 & 2000 & 3200 & 0.2 \\
Calcium-silicate & 0.01 & 1800 & 2500 & 0.2 \\
\hline
\end{tabular}

Table 1: Material properties and dimensions: Internal loss factor, $\eta_{\text {int }}$; Density, $\rho$; Quasi-longitudinal wavespeed, $c_{L}$; Poisson ratio, $\nu$.

The FEM ensemble of junctions was created by considering different combinations of walls and floors with different dimensions. For floors the length perpendicular to the junction was $3.5 \mathrm{~m}, 4.5 \mathrm{~m}$ or $5.5 \mathrm{~m}$ and for walls the height was $2.5 \mathrm{~m}$. Following the approach in ISO 10848-1 [8], these lengths were selected so that there was a $10 \%$ difference between the plates that formed each junction. The junction length was $4 \mathrm{~m}$, $5 \mathrm{~m}$ or $6 \mathrm{~m}$. This provided a set of 27 junctions with different dimensions for every case with different materials and thicknesses. The final output for every case was obtained by averaging the results of these 27 different junctions. Window and door openings were not included, primarily because there are too many different possibilities for their position in relation to the junction line. Previous work [1, 25] used FEM to model the effect of window openings in heavyweight walls and, if needed, this provides a rule-of-thumb which can be used to determine a simple estimate for the increase in $K_{i j}$ due to a window opening.

The FEM models require a frequency-dependent loss factor for the walls and floors which is given by

$$
\frac{1}{\sqrt{f}}+\eta_{i n t}
$$

where $\eta_{\text {int }}$ is the internal loss factor. This was used to simulate the total loss factor that was likely to occur when heavyweight walls/floors are connected to many other walls and floors in situ [26]. The internal loss factor for heavyweight walls and floors is typically no more than 0.01 ; hence the total loss factor is primarily determined by the sum of the coupling loss factors in the low- and mid-frequency ranges. Numerical simulations with SFEM [18] indicate that when simulating coupled walls and floors using loss factors greater than 0.01 there is no significant change in $K_{i j}$. Damping 
values were calculated for each one-third octave band centre frequency and applied to all frequencies that were calculated within that one-third octave band.

\section{$3 \quad$ Results and analysis}

\subsection{Optimising the choice of independent and dependent vari- ables to determine $K_{i j}$}

In ISO 15712 and EN 12354 the independent variable used to determine $K_{i j}$ is the ratio of the mass per unit areas, $M$, given by

$$
M=\log _{10}\left(\frac{m_{\perp i}^{\prime}}{m_{i}^{\prime}}\right)
$$

where $m_{i}^{\prime}$ is the mass per unit area $\left(\mathrm{kg} / \mathrm{m}^{2}\right)$ of element $\mathrm{i}$ in the transmission path from $\mathrm{i}$ to $\mathrm{j}$ and $m_{\perp i}^{\prime}$ is the mass per unit area $\left(\mathrm{kg} / \mathrm{m}^{2}\right)$ of the other perpendicular element in the junction.

An alternative independent variable to $M$ proposed by Crispin et al [17] is the ratio of characteristic moment impedances, $\Psi / \chi$ [16], given by

$$
\frac{\Psi}{\chi}=\sqrt[4]{\frac{m_{\perp i}^{\prime} B_{\perp i}^{3}}{m_{i}^{\prime} B_{i}^{3}}}=\frac{m_{\perp i}^{\prime}}{m_{i}^{\prime}}\left(\frac{f_{c, \perp i}}{f_{c, i}}\right)^{-3 / 2}=\frac{m_{\perp i}^{\prime}}{m_{i}^{\prime}}\left(\frac{h_{\perp i} c_{L, \perp i}}{h_{i} c_{L, i}}\right)^{3 / 2}
$$

where $B$ is the bending stiffness per unit width $(\mathrm{Nm}), f_{c}$ is the critical frequency $(\mathrm{Hz})$, $c_{L}$ is the quasi-longitudinal wavespeed $(\mathrm{m} / \mathrm{s})$.

These two independent variables are now assessed with the dependent values of $K_{i j}$ and $\gamma_{i j}$. Wave theory for L-, T- and X-junctions is used to identify the optimal choice of independent and dependent variables to determine $K_{i j}$. L-junctions are suitable for this illustration because there are fewer permutations to consider than with $\mathrm{T}$ or X-junctions where transmission differs around the corner and across the straight section. In addition, an incident bending wave always causes all three wave types to be transmitted to the other plate with the bending and in-plane model. Wave theory was used instead of FEM because it provides a clearer illustration of the general trends due to significant variation within an ensemble of FEM values from different sizes of walls and floors.

For transmission around the corner, the results for L-, T- and X-junctions are shown in Fig. 2, Fig. 3 and Fig. 4 respectively. Note that for the X-junction the results are only shown for bending wave theory as they are identical to those for bending and in-plane theory. The trends for all three junctions are similar. When $K_{12}$ is plotted against $M$ as shown in (a) it is evident that the individual $K_{12}$ values are scattered around their respective regression curve. When $\gamma_{12}$ rather than $K_{12}$ is plotted against $M$ as shown in (b) the scatter is reduced at $M=1$ but there is no significant reduction in scatter at other values of $M$. The reason that plotting $K_{i j}$ results in a range of values at $M=1$ or $\Psi / \chi=1$ is due to the normalisation that has been chosen to define $K_{i j}$ which uses the critical frequency of plate $\mathrm{j}$ as indicated in Eq. (4). This is avoided by using $\gamma_{i j}$ instead of $K_{i j}$. However it is only with the 
bending only model that the data points cluster closely around the regression line. The reason for this is that the bending and in-plane model uses average values over the mid- and high-frequency ranges where there are bending and in-plane waves. When $K_{12}$ is plotted against $\Psi / \chi M$ as shown in (c), the scatter is reduced at most values of $\Psi / \chi$ but remains significant when $\Psi / \chi=1$. However, when $\gamma_{12}$ is plotted against $\Psi / \chi$ as shown in (d) the scatter is reduced at all values of $\Psi / \chi$.

\begin{tabular}{lccccc}
\hline $\begin{array}{l}\text { Frequency } \\
\text { range }\end{array}$ & Junction & $\begin{array}{c}K_{12} \\
\text { versus } M\end{array}$ & $\begin{array}{c}K_{12} \\
\text { versus } \Psi / \chi\end{array}$ & $\begin{array}{c}-10 \log _{10}\left(\gamma_{12}\right) \\
\text { versus } M\end{array}$ & $\begin{array}{c}-10 \log _{10}\left(\gamma_{12}\right) \\
\text { versus } \Psi / \chi\end{array}$ \\
\hline \multirow{3}{*}{ Low } & $\mathrm{L}$ & 0.92 & 0.90 & 0.99 & 1.00 \\
& $\mathrm{~T}$ & 0.89 & 0.97 & 0.87 & 0.99 \\
& $\mathrm{X}$ & 0.85 & 0.96 & 0.89 & 0.99 \\
\multirow{3}{*}{ Mid } & $\mathrm{L}$ & 0.91 & 0.89 & 0.98 & 0.99 \\
& $\mathrm{~T}$ & 0.89 & 0.96 & 0.87 & 0.99 \\
& $\mathrm{X}$ & 0.85 & 0.96 & 0.89 & 0.99 \\
\multirow{2}{*}{ High } & $\mathrm{L}$ & 0.88 & 0.86 & 0.97 & 0.98 \\
& $\mathrm{~T}$ & 0.86 & 0.95 & 0.84 & 0.98 \\
& $\mathrm{X}$ & 0.85 & 0.96 & 0.89 & 0.99 \\
\hline
\end{tabular}

Table 2: Coefficient of determination $\left(R^{2}\right)$ for transmission around the corner with a cubic line fit. The low-frequency range covers one-third octave bands from $50 \mathrm{~Hz}$ to $200 \mathrm{~Hz}$, mid-frequency range from $250 \mathrm{~Hz}$ to $1 \mathrm{kHz}$, and high-frequency range from $1.25 \mathrm{kHz}$ to $5 \mathrm{kHz}$.

\begin{tabular}{lccccc}
\hline $\begin{array}{l}\text { Frequency } \\
\text { range }\end{array}$ & Junction & $\begin{array}{c}K_{13} \\
\text { versus } M\end{array}$ & $\begin{array}{c}K_{13} \\
\text { versus } \Psi / \chi\end{array}$ & $\begin{array}{c}-10 \log _{10}\left(\gamma_{13}\right) \\
\text { versus } M\end{array}$ & $\begin{array}{c}-10 \log _{10}\left(\gamma_{13}\right) \\
\text { versus } \Psi / \chi\end{array}$ \\
\hline \multirow{2}{*}{ Low } & $\mathrm{T}$ & 0.92 & 1.00 & 0.92 & 1.00 \\
& $\mathrm{X}$ & 0.94 & 0.99 & 0.95 & 1.00 \\
\hline \multirow{2}{*}{ Mid } & $\mathrm{T}$ & 0.92 & 0.94 & 0.93 & 0.94 \\
& $\mathrm{X}$ & 0.95 & 0.97 & 0.97 & 0.97 \\
\multirow{2}{*}{ High } & $\mathrm{T}$ & 0.94 & 0.93 & 0.96 & 0.93 \\
& $\mathrm{X}$ & 0.95 & 0.95 & 0.97 & 0.95 \\
\hline
\end{tabular}

Table 3: Coefficient of determination $\left(R^{2}\right)$ for transmission across the straight section with a cubic line fit. The low-frequency range covers one-third octave bands from 50 $\mathrm{Hz}$ to $200 \mathrm{~Hz}$, mid-frequency range from $250 \mathrm{~Hz}$ to $1 \mathrm{kHz}$, and high-frequency range from $1.25 \mathrm{kHz}$ to $5 \mathrm{kHz}$.

For transmission across the straight section, the results for $\mathrm{T}$ - and $\mathrm{X}$-junctions are shown in Fig. 5 and Fig. 6 respectively. In the low-frequency range, plotting $\gamma_{13}$ against $\Psi / \chi$ significantly reduces the scatter compared to $K_{13}$ against $M$. This effect is less evident for the mid- and high-frequency ranges as scatter still occurs.

The coefficients of determination $\left(R^{2}\right)$ relating to the regression curves are shown in Table 2 for transmission around the corner of L-, T- and X-junctions, and Table 3 for transmission across the straight section of $\mathrm{T}$ - and $\mathrm{X}$-junctions. $R^{2}$ describes the 



- Wave theory (Bending only) : Low-frequency range

- Wave theory (Bending and in-plane) : Mid-frequency range

- Wave theory (Bending and in-plane) : High-frequency range

— Regression curve: Low-frequency range

- Regression curve: High-frequency range

Figure 2: Comparison of L-junction data calculated using wave theory. (a) $K_{12}$ versus $M$, (b) $-10 \log _{10}\left(\gamma_{12}\right)$ versus $M$, (c) $K_{12}$ versus $\Psi / \chi,-10 \log _{10}\left(\gamma_{12}\right)$ versus $M$, (d) $-10 \log _{10}\left(\gamma_{12}\right)$ versus $\Psi / \chi$.

fraction of the variation in the outcome that can be explained by the regression curve. For transmission around the corner, $R^{2}$ is largest for $\gamma_{12}$ versus $\Psi / \chi$ which indicates that this combination is optimal for the low-, mid- and high-frequency ranges. However, for transmission across the straight section in the low- and mid-frequency ranges, $R^{2}$ is similarly high for $\gamma_{13}$ versus $\Psi / \chi$ and $K_{13}$ versus $\Psi / \chi$. lotting $K_{i j}$ results in a range of values at $M=1$ or $\Psi / \chi=1$ is due to the normalisation that has been chosen to define $K_{i j}$ which uses the critical frequency of plate $\mathrm{j}$ as indicated in Eq. (4) This is avoided by using $\gamma_{i j}$ instead of $K_{i j}$. However it is only with the bending only model that the data points cluster closely around the regression line. The reason for this is uses average values over the mid- and high-frequency ranges where there are bending and in-plane waves.

These calculations for transmission around the corner and across the straight section confirm that plotting $\gamma_{i j}$ against $\Psi / \chi$ significantly reduces scatter in the lowfrequency range (bending only model) but that the effect is less significant in the mid- and high-frequency ranges (bending and in-plane model). he The low-frequency range is critical in determining the single-number quantities used to describe airborne and impact sound insulation; hence this provides the motivation to consider $\Psi / \chi$ and $\gamma_{i j}$ for all junctions rather than $M$ and $K_{i j}$. Based on these findings, all regression 

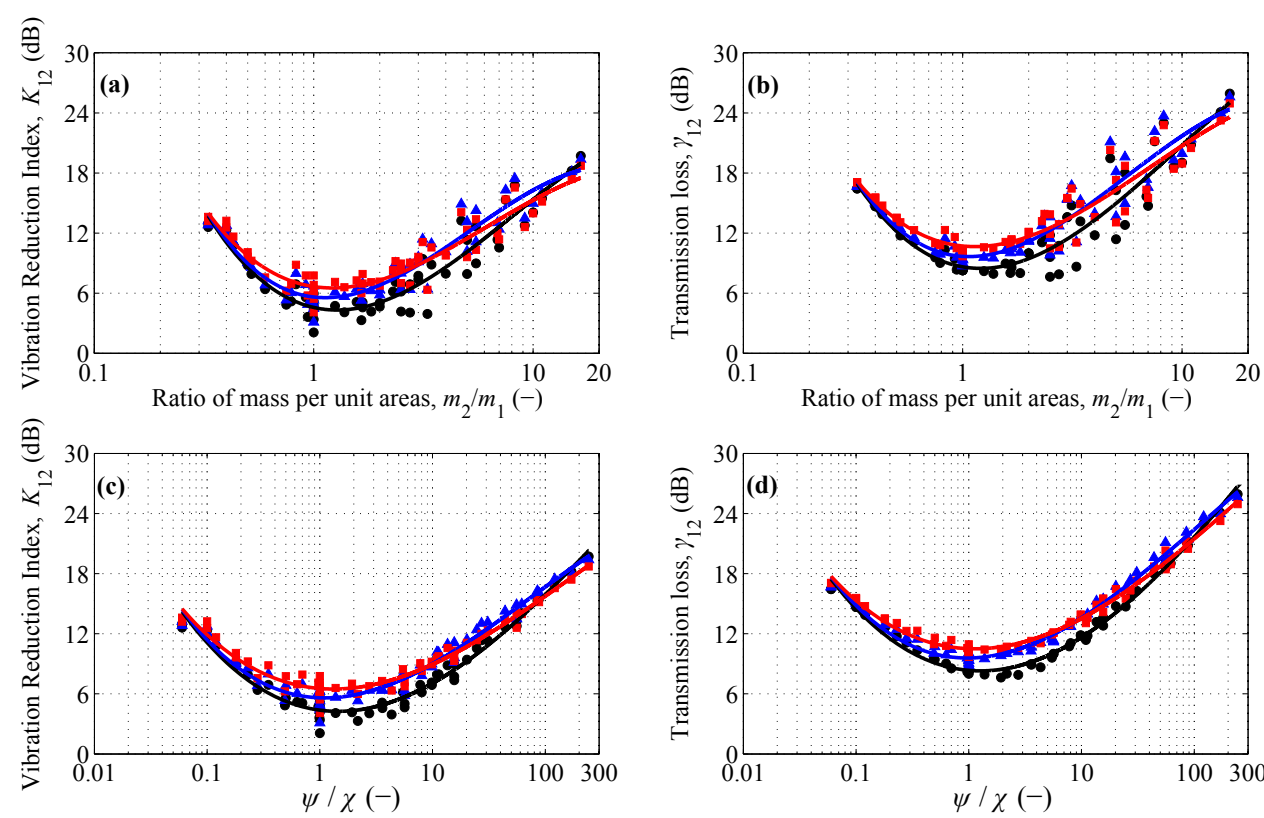

- Wave theory (Bending only) : Low-frequency range

- Wave theory (Bending and in-plane) : Mid-frequency range

- Wave theory (Bending and in-plane) : High-frequency range

— Regression curve: Low-frequency range - Regression curve: Mid-frequency range — Regression curve: High-frequency range

Figure 3: Comparison of T-junction data (transmission around the corner) calculated using wave theory. (a) $K_{12}$ versus $M$, (b) $-10 \log _{10}\left(\gamma_{12}\right)$ versus $M$, (c) $K_{12}$ versus $\Psi / \chi,(d)-10 \log _{10}\left(\gamma_{12}\right)$ versus $\Psi / \chi$.

curves in the next section plot $\gamma_{i j}$ against $\Psi / \chi$ for all junctions where the data points are determined from both FEM and wave theory data.

\subsection{Regression curves}

Based on the findings in the previous section, regression analysis was carried out on the dependent variable, $\gamma_{i j}$, from Actran, SFEM and wave theory using the independent variable, $P C$, which is defined as

$$
P C=\log _{10}(\Psi / \chi)
$$

The Actran and SFEM ensemble included $\gamma_{i j}$ values relating to the same $\Psi / \chi$ and these were averaged before carrying out the regression analysis. Previous regression analysis using wave theory [6] indicated that cubic or quadratic expressions tend to provide the best fit for transmission around the corner, and quadratic or linear expressions tend to provide the best fit for transmission across the straight section of $\mathrm{T}$ - and $\mathrm{X}$-junctions. In this paper all the regression curves are cubic expressions as these gave the highest coefficients of determination, $R^{2}$, and the use of a single expression is potentially convenient for implementation in European and International 

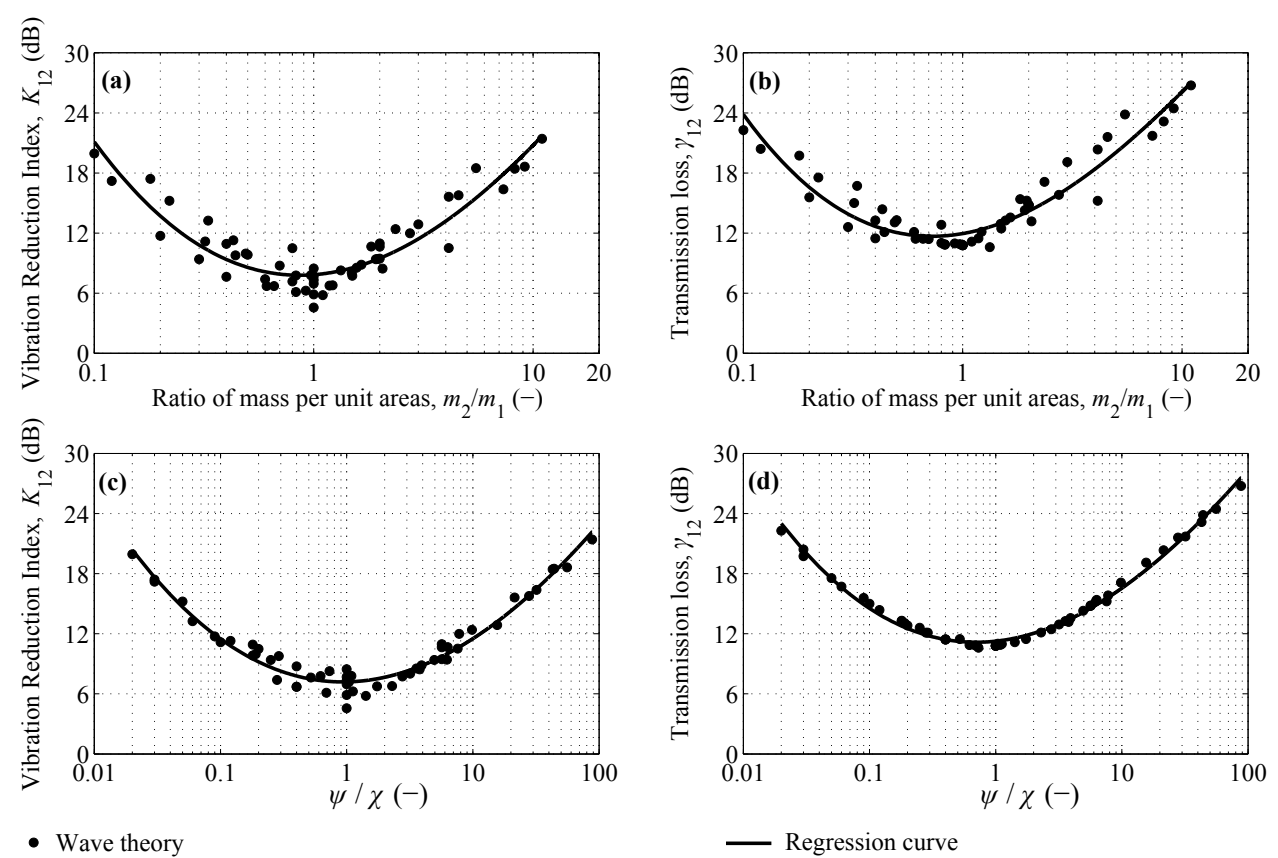

Figure 4: Comparison of X-junction data (transmission around the corner) calculated using wave theory. (a) $K_{12}$ versus $M$, (b) $-10 \log _{10}\left(\gamma_{12}\right)$ versus $M$, (c) $K_{12}$ versus $\Psi / \chi,(d)-10 \log _{10}\left(\gamma_{12}\right)$ versus $\Psi / \chi$.

Standards. The regression curves relating $P C$ to $\gamma_{i j}$ are given in Table 4 and these are referred to in the next section as the new $K_{i j}$ relationships.

For L-junctions, Fig. 7(a) shows that in the low-frequency range, wave theory values were $\approx 2 \mathrm{~dB}$ lower than Actran and SFEM; hence the cubic regression curve gives an average value. In the mid-frequency range, Fig. 7(b) shows that wave theory was $\approx 3 \mathrm{~dB}$ lower than Actran and SFEM, but in the high-frequency range there was greater scatter with some Actran data giving significantly different transmission loss to SFEM and wave theory. A single regression line was used for the mid- and high-frequency data as the $\gamma_{i j}$ values clustered together.

For vibration transmission around the corner of the T-junctions, Fig. 8(a) shows reasonable agreement between wave theory, Actran and SFEM in the low-frequency range although Actran gives higher transmission loss values than SFEM and wave theory when $\Psi / \chi ; 1$. For the mid- and high-frequency ranges shown in Fig. 8(b) the $\gamma_{i j}$ values clustered together; hence only a single regression line was determined.

For vibration transmission across the straight section of the T-junctions, Fig. 9(a) shows close agreement between wave theory, Actran and SFEM for the low-frequency range. In contrast to transmission around the corner of the T-junctions, Fig. 9(b) shows two distinct sets of $\gamma_{i j}$ values for the mid- and high-frequency ranges. 

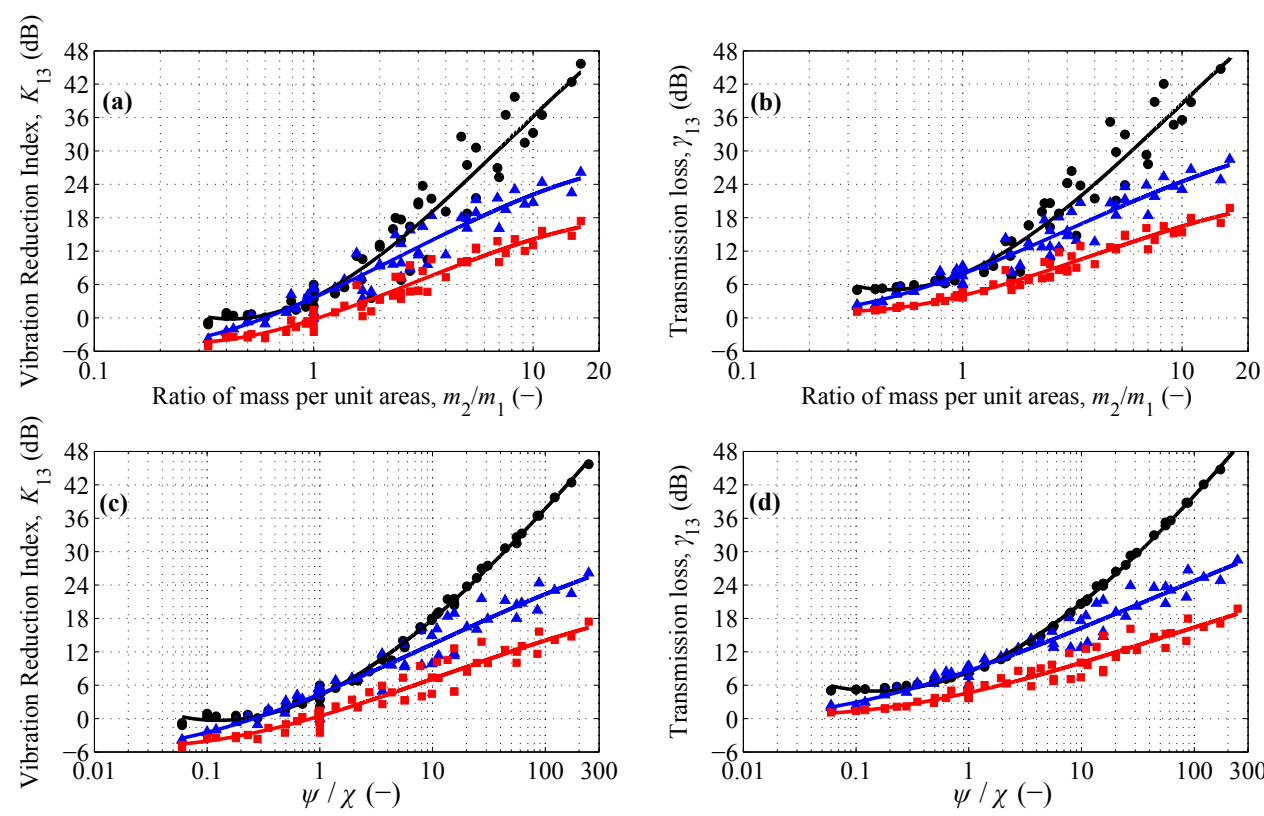

- Wave theory (Bending only) : Low-frequency range

— Regression curve: Low-frequency range

- Wave theory (Bending and in-plane) : Mid-frequency range

- Wave theory (Bending and in-plane) : High-frequency range

Figure 5: Comparison of T-junction data (transmission across the straight section) calculated using wave theory. (a) $K_{13}$ versus $M$, (b) $-10 \log _{10}\left(\gamma_{13}\right)$ versus $M$, (c) $K_{13}$ versus $\Psi / \chi,(d)-10 \log _{10}\left(\gamma_{13}\right)$ versus $\Psi / \chi$.

For vibration transmission around the corner of the X-junctions, Fig. 10(a) shows reasonable agreement between wave theory, Actran and FEM in the low-frequency range, although Actran gives higher transmission loss values than SFEM and wave theory when $\Psi / \chi i 1$. Fig. 10(b) shows the mid- and high-frequency ranges; however, allowing in-plane wave generation at the junction does not change the transmission loss from the bending only model when plates 1 and 3 are the same and plates 2 and 4 are the same. Hence the wave theory data are the same as shown on Fig. 10(a). Therefore regression was carried out on the low-, mid- and high-frequency data due to the similarity in the results and to reduce the number of regression curves required in the standards. This is justified by the $R^{2}$ value of 0.95 .

For vibration transmission across the straight section of the $\mathrm{X}$-junctions, the findings were similar to those across the straight section of the T-junction for the lowfrequency range in Fig. 11(a) and the mid- and high-frequency ranges in Fig. 11(b).

There are general tendencies for wave theory to give slightly lower transmission loss values than Actran and SFEM in the low-frequency range when $\Psi / \chi_{i} 1$, and for Actran to give higher transmission loss values than SFEM. Whilst these approaches to prediction have all been validated against measurements, there is no single approach that can be identified as definitive. For this reason it is logical to use regression on the 

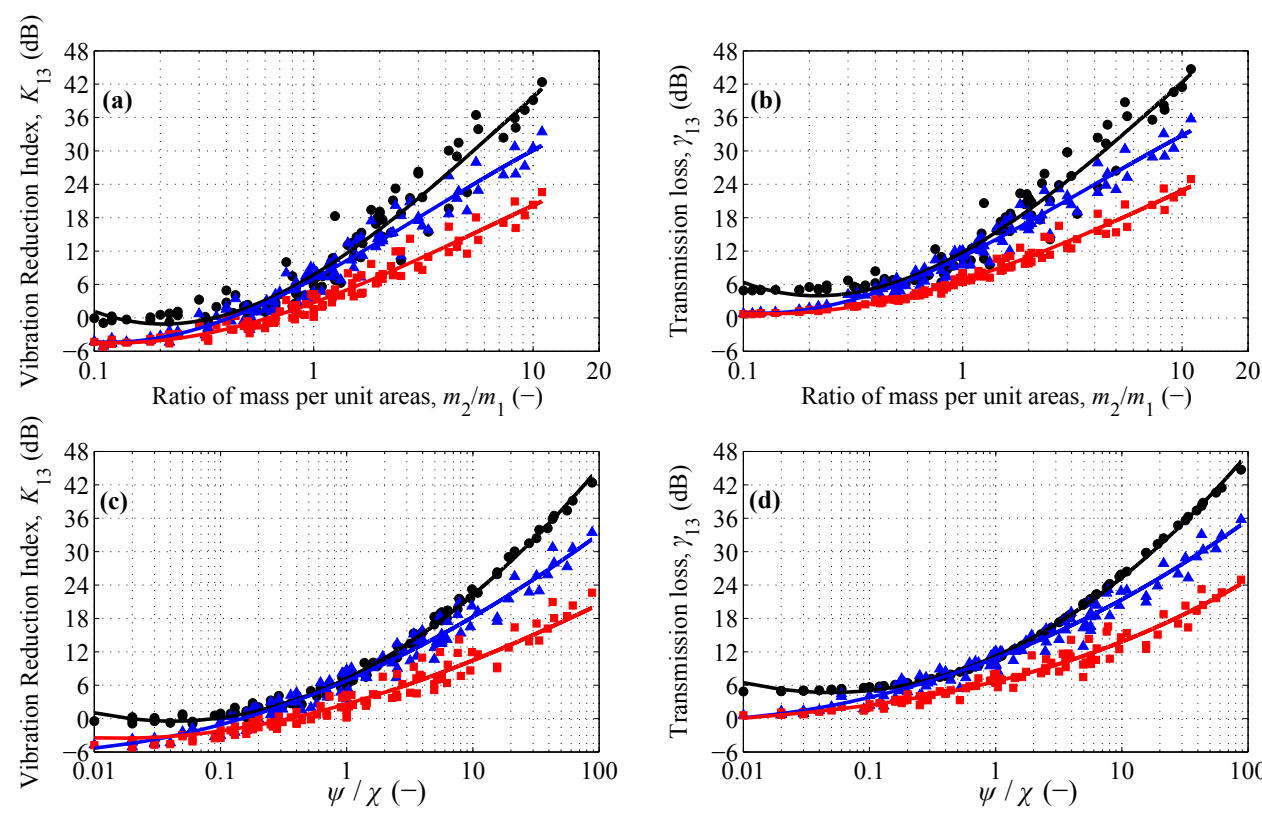

- Wave theory (Bending only) : Low-frequency range

- Regression curve: Low-frequency range

- Wave theory (Bending and in-plane) : Mid-frequency range

- Wave theory (Bending and in-plane) : High-frequency range

Figure 6: Comparison of $\mathrm{X}$-junction data (transmission across the straight section) calculated using wave theory. (a) $K_{13}$ versus $M$, (b) $-10 \log _{10}\left(\gamma_{13}\right)$ versus $M$, (c) $K_{13}$ versus $\Psi / \chi,(d)-10 \log _{10}\left(\gamma_{13}\right)$ versus $\Psi / \chi$.

combination of data from Actran, SFEM and wave theory so that the result represents the average of many similar junctions in buildings ranging from residential housing (relatively small walls and floors) to commercial buildings (relatively large walls and floors).

\subsection{Implications for the estimations in European and Inter- national Standards}

This section investigates the implications of using the new $K_{i j}$ relationships in Table 4 when estimating the sound insulation using the prediction model in the European and International Standards. The new $K_{i j}$ relationships represent average values for similar junctions so they do not apply to any specific junction in a building; this is the essence of SEA, namely that the result should apply to an ensemble average result from many similar buildings. However, it is unusual to have access to large datasets of sound insulation for nominally identical buildings, and the prediction model is often used by acoustic engineers and architects to assess the sound insulation in individual buildings. For this reason, this section presents the differences between measured and predicted sound insulation in terms of average, minimum and maximum values. 


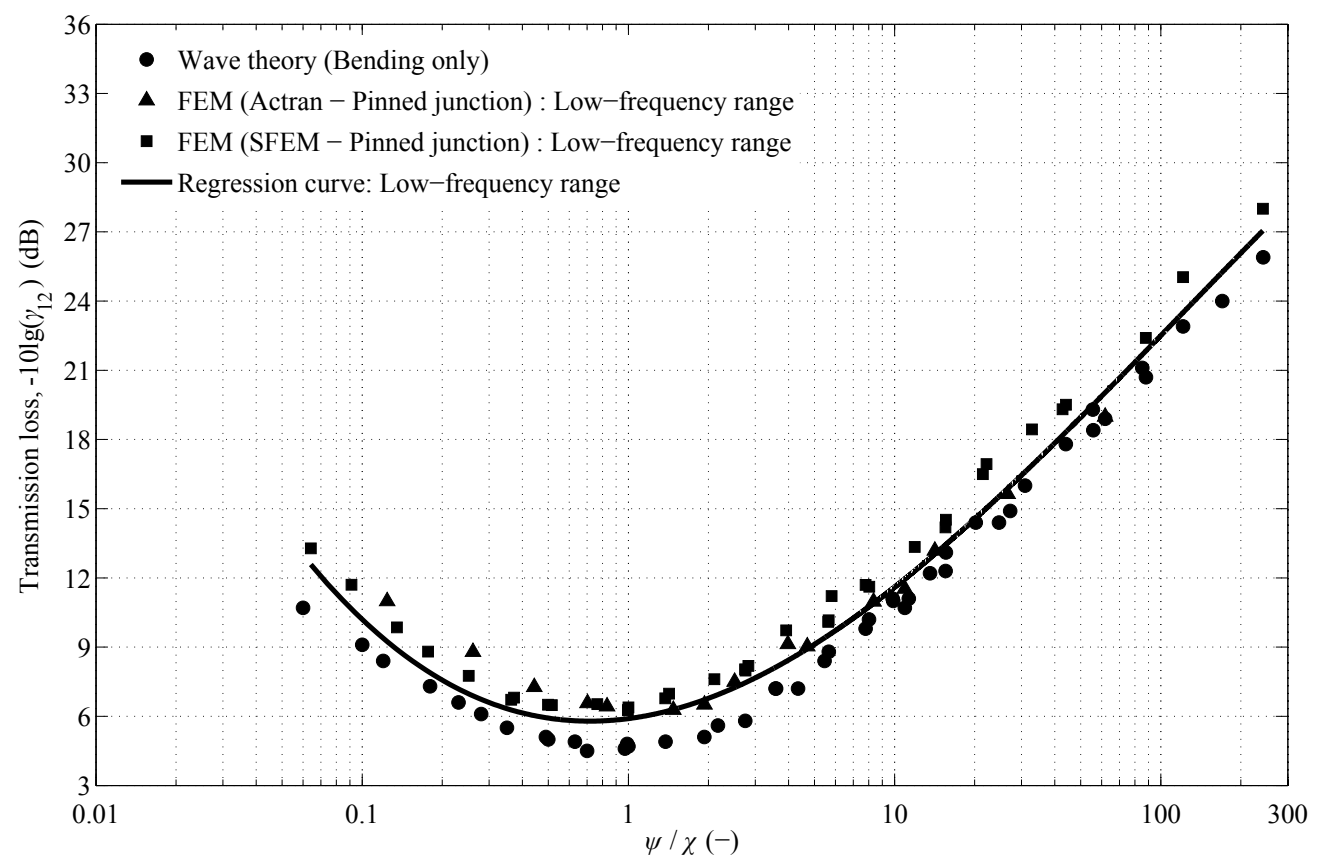

(a)

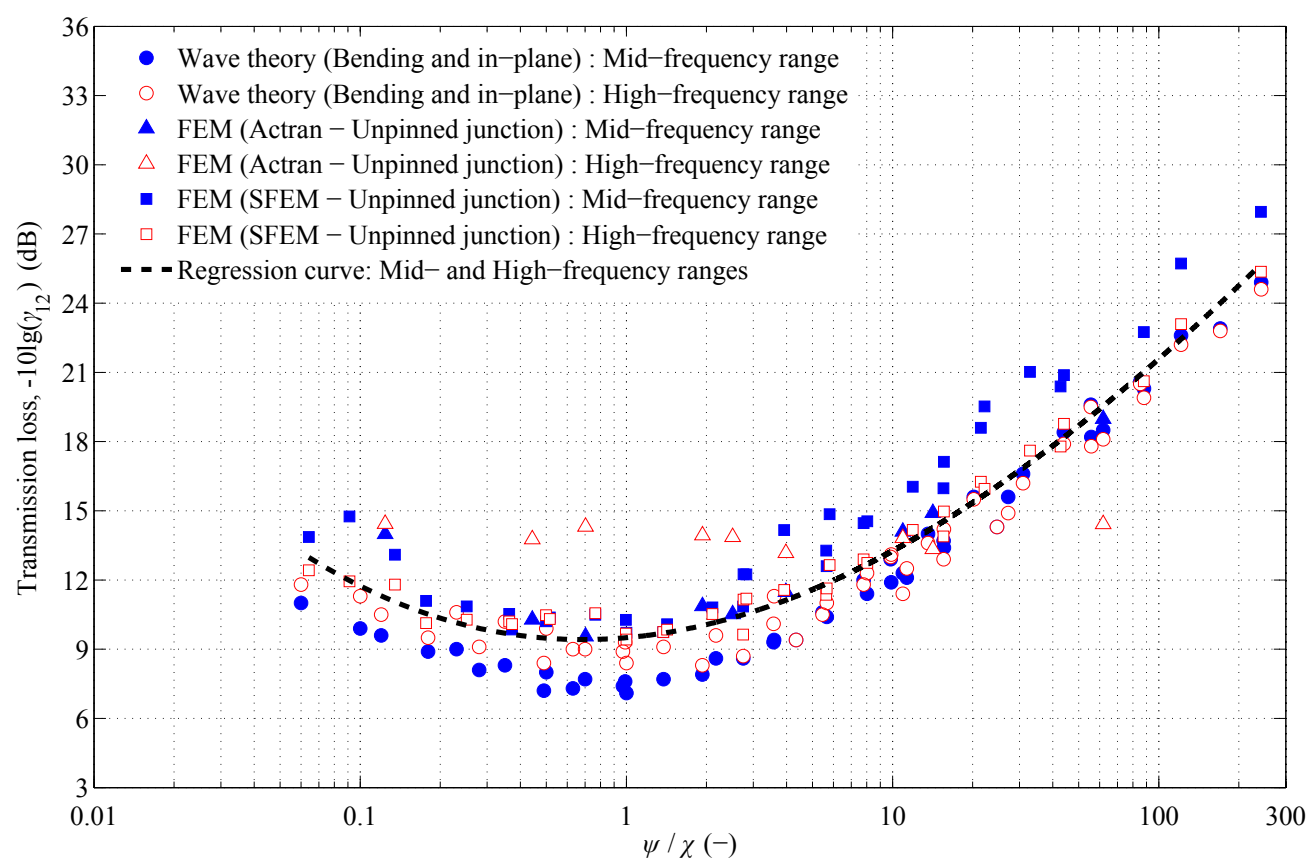

(b)

Figure 7: L-junctions $\left(-10 \log _{10}\left(\gamma_{12}\right)\right.$ versus $\left.\Psi / \chi\right)$. Comparison of wave theory and FEM in (a) the low-frequency range and (b) the mid- and high-frequency ranges. 


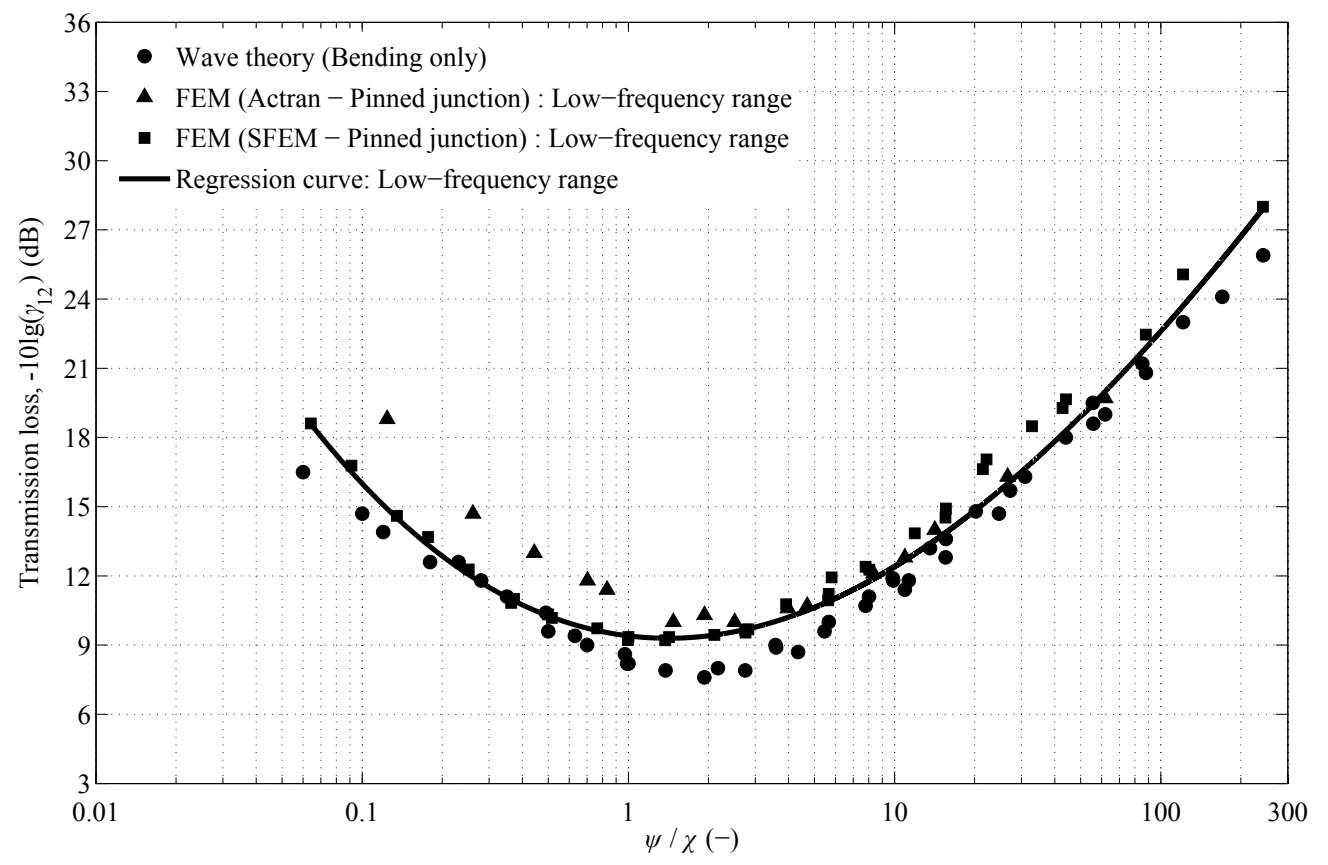

(a)

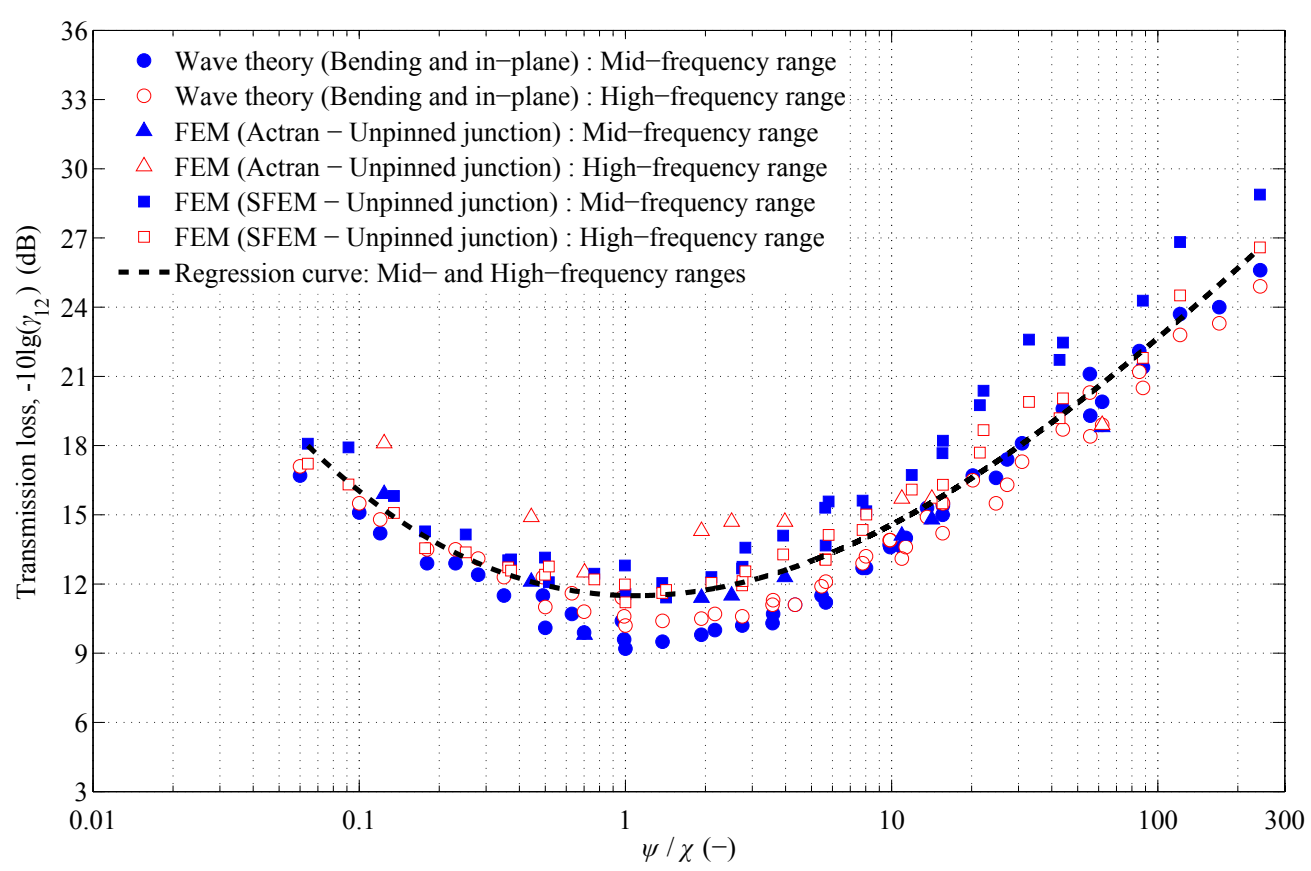

(b)

Figure 8: T-junctions $\left(-10 \log _{10}\left(\gamma_{12}\right)\right.$ versus $\left.\Psi / \chi\right)$ transmission around the corner. Comparison of wave theory and FEM in (a) the low-frequency range and (b) the midand high-frequency ranges. 


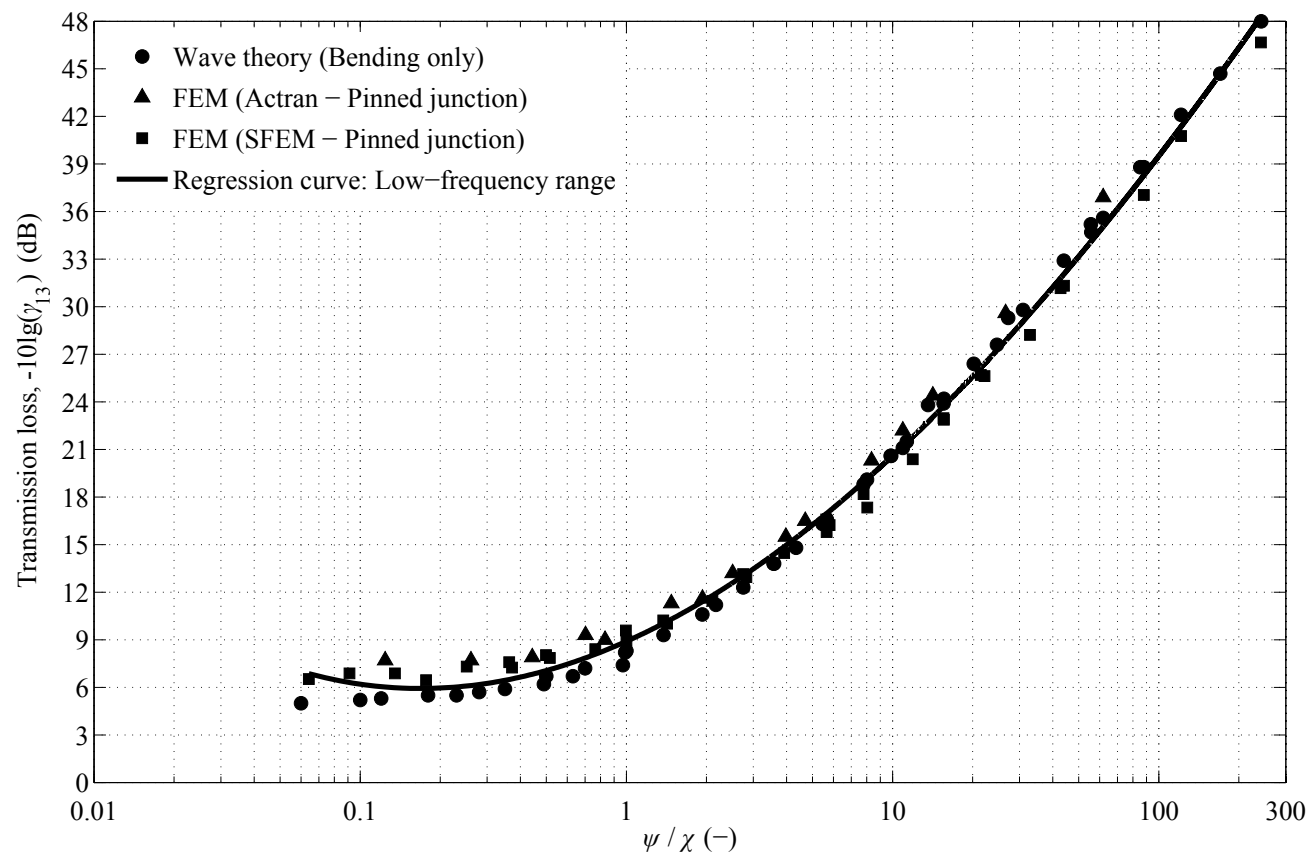

(a)

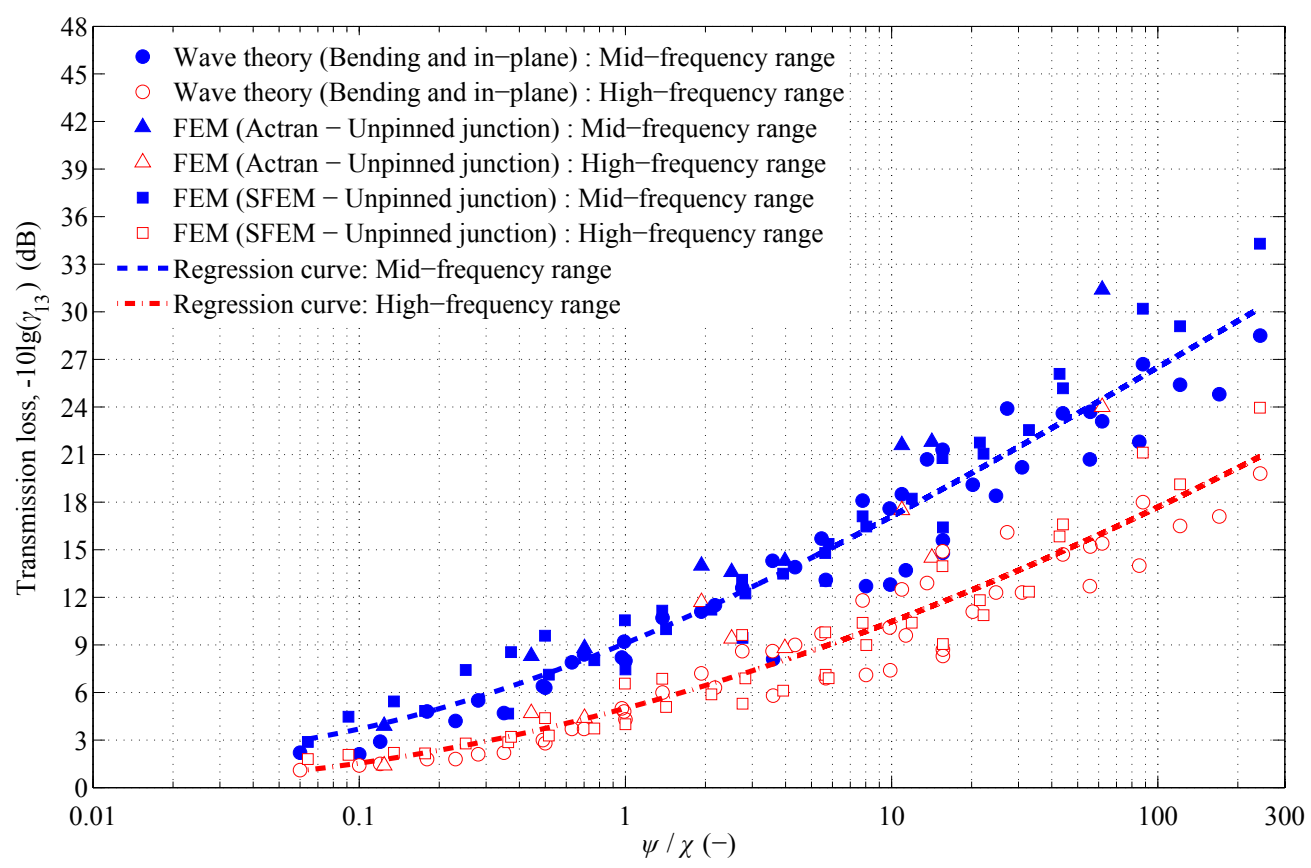

(b)

Figure 9: T-junctions $\left(-10 \log _{10}\left(\gamma_{13}\right)\right.$ versus $\left.\Psi / \chi\right)$ transmission across the straight section. Comparison of wave theory and FEM in (a) the low-frequency range and (b) the mid- and high-frequency ranges. 


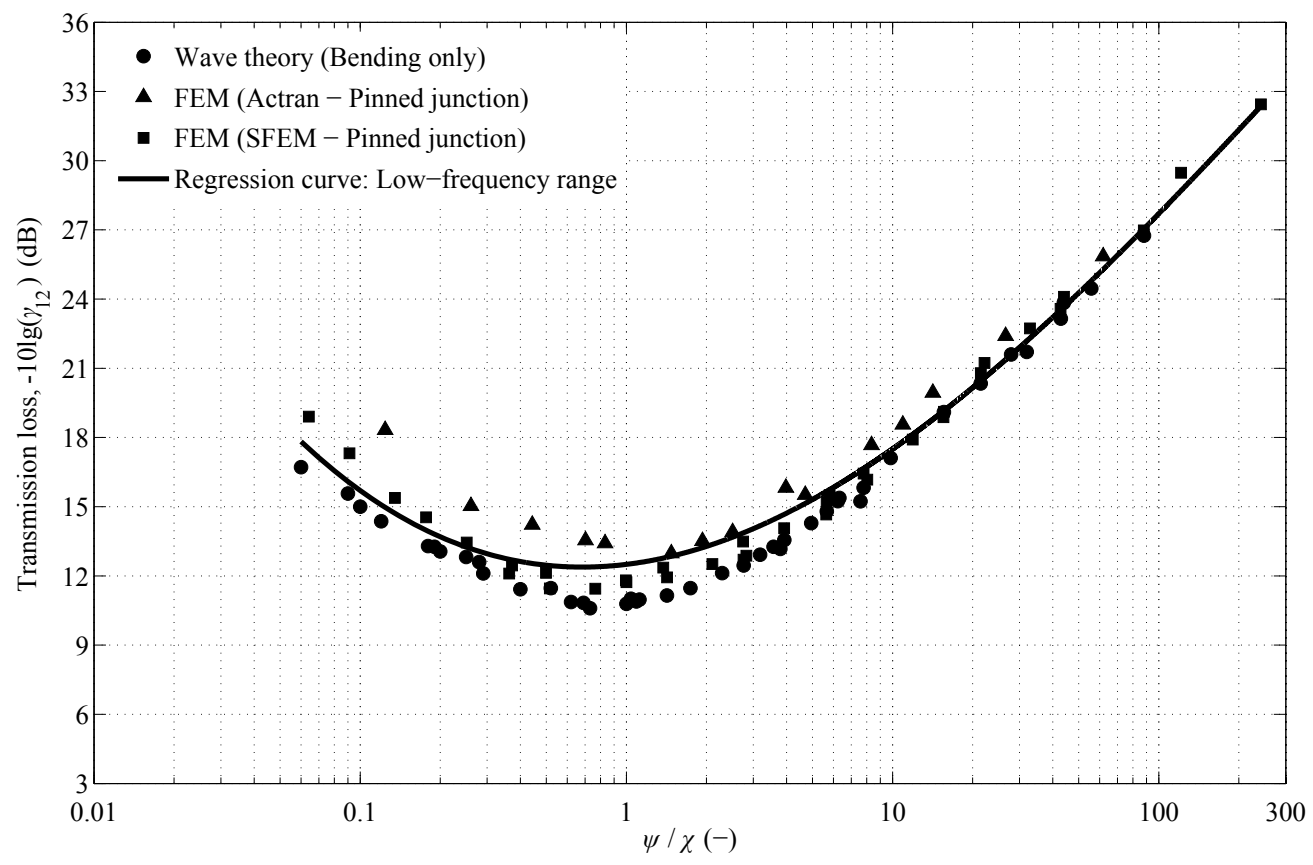

(a)

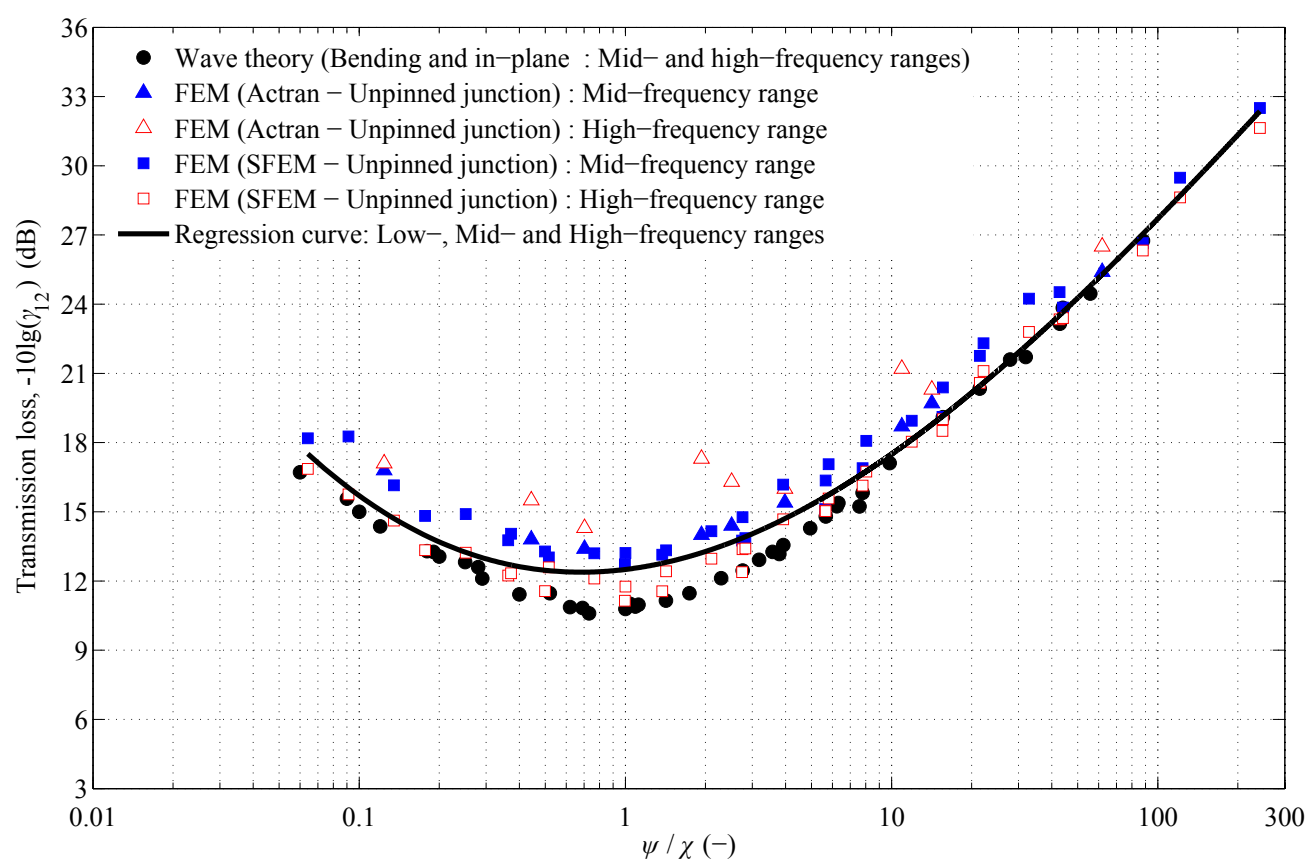

(b)

Figure 10: $\mathrm{X}$-junctions $\left(-10 \log _{10}\left(\gamma_{12}\right)\right.$ versus $\left.\Psi / \chi\right)$ transmission around the corner. Comparison of wave theory and FEM in (a) the low-frequency range and (b) the midand high-frequency ranges. 


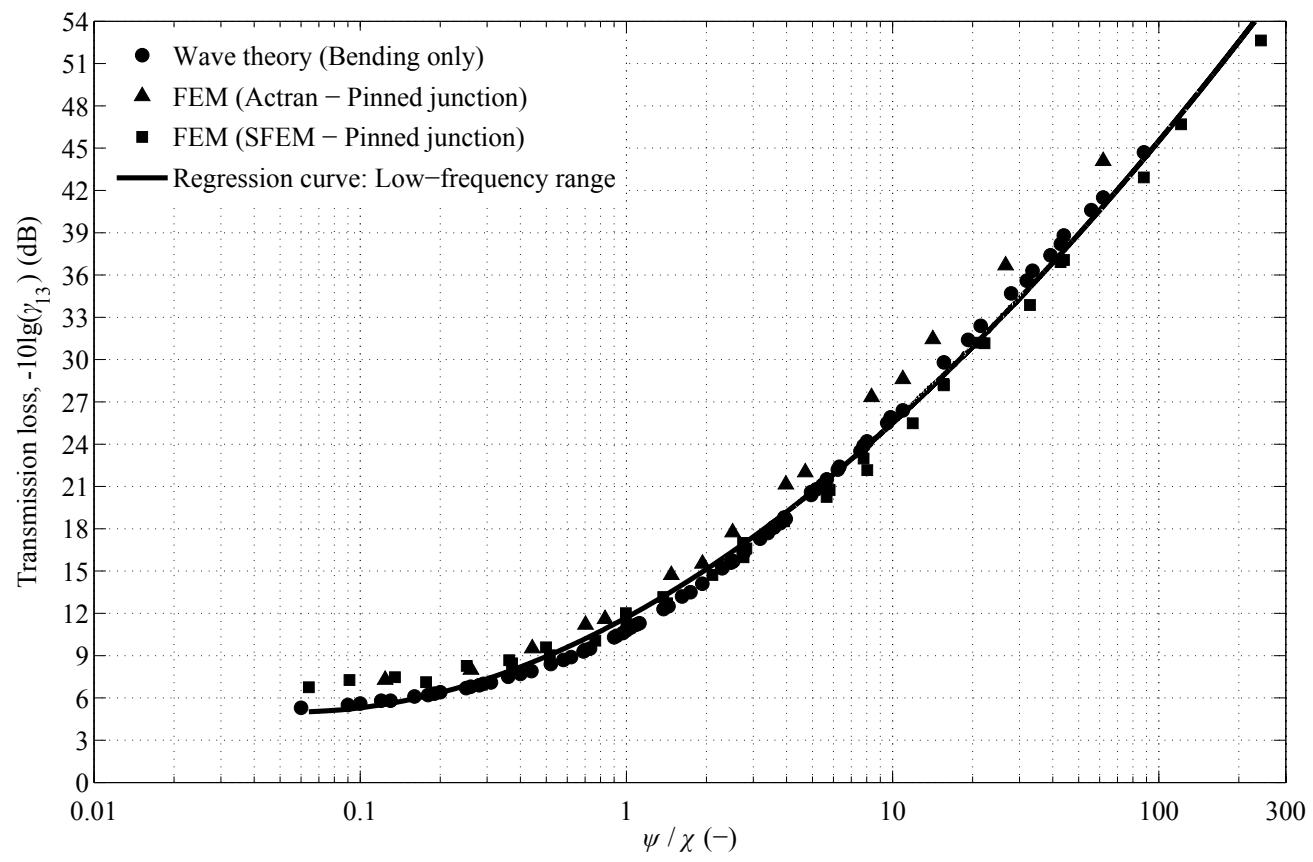

(a)

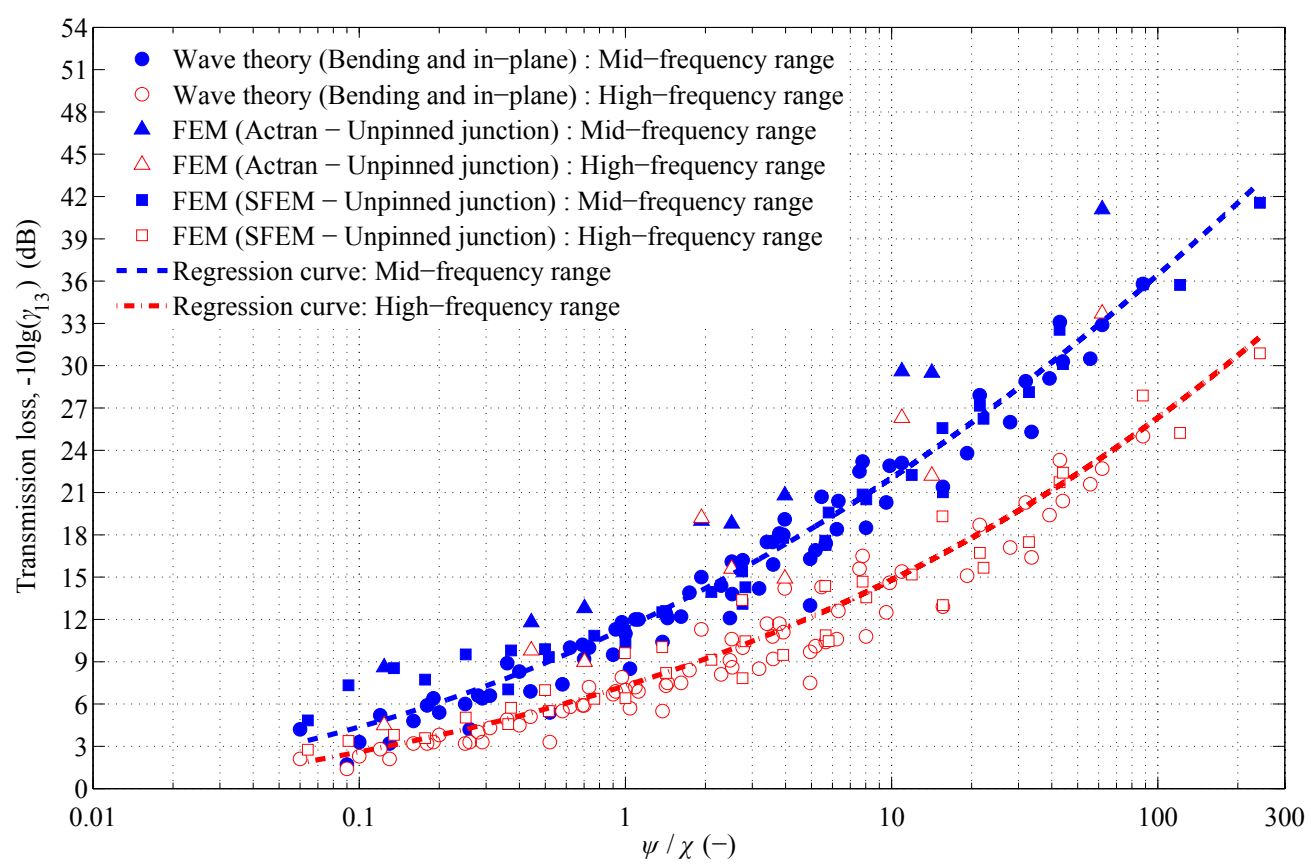

(b)

Figure 11: X-junctions $\left(-10 \log _{10}\left(\gamma_{13}\right)\right.$ versus $\left.\Psi / \chi\right)$ transmission across the straight section. Comparison of wave theory and FEM in (a) the low-frequency range and (b) the mid- and high-frequency ranges. 


\begin{tabular}{|c|c|c|}
\hline Junction & $\begin{array}{l}\text { Freq. } \\
\text { range }\end{array}$ & Formula \\
\hline \multicolumn{3}{|l|}{ L-junction } \\
\hline \multirow[t]{2}{*}{1} & Low & $T L_{12}=-0.8 P C^{3}+5 P C^{2}+1.5 P C+5.9\left(R^{2}=0.97\right)$ \\
\hline & $\begin{array}{l}\text { Mid \& } \\
\text { High }\end{array}$ & $T L_{12}=-0.24 P C^{3}+3 P C^{2}+P C+9.5\left(R^{2}=0.88\right)$ \\
\hline T-junction & Low & $\begin{array}{l}T L_{12}=-0.4 P C^{3}+4.8 P C^{2}-1.4 P C+9.4\left(R^{2}=0.95\right) \\
T L_{13}=-0.3 P C^{3}+4.5 P C^{2}+7.5 P C+8.9\left(R^{2}=0.99\right)\end{array}$ \\
\hline \multirow[t]{2}{*}{$\mathbf{3}$} & Mid & $\begin{array}{c}T L_{12}=-0.43 P C^{3}+3.8 P C^{2}-0.3 P C+11.5\left(R^{2}=0.89\right) \\
T L_{13}=-0.2 P C^{3}+1.3 P C^{2}+6.9 P C+9.1\left(R^{2}=0.92\right)\end{array}$ \\
\hline & High & $\begin{array}{c}T L_{12}=-0.43 P C^{3}+3.8 P C^{2}-0.3 P C+11.5\left(R^{2}=0.89\right) \\
T L_{13}=-0.04 P C^{3}+P C^{2}+4.5 P C+5\left(R^{2}=0.87\right)\end{array}$ \\
\hline \multirow[t]{2}{*}{$\mathrm{X}$-junction } & Low & $\begin{array}{c}T L_{12}=-0.5 P C^{3}+4.1 P C^{2}+1.4 P C+12.5\left(R^{2}=0.95\right) \\
T L_{13}=-0.2 P C^{3}+3.7 P C^{2}+10.3 P C+11.7\left(R^{2}=0.99\right)\end{array}$ \\
\hline & Mid & $T L_{12}=-0.5 P C^{3}+4.1 P C^{2}+1.4 P C+12.5\left(R^{2}=0.95\right)$ \\
\hline 1 & High & $\begin{array}{c}T L_{12}=-0.5 P C^{3}+4.1 P C^{2}+1.4 P C+12.5\left(R^{2}=0.95\right) \\
T L_{13}=0.2 P C^{3}+1.4 P C^{2}+5.9 P C+7.3\left(R^{2}=0.95\right)\end{array}$ \\
\hline
\end{tabular}

Table 4: Regression curves for the transmission loss $\left(T L_{i j}=-10 \log _{10}\left(\gamma_{i j}\right)\right)$ as a function of $P C$. The low-frequency range covers one-third octave bands from $50 \mathrm{~Hz}$ to $200 \mathrm{~Hz}$, mid-frequency range from $250 \mathrm{~Hz}$ to $1 \mathrm{kHz}$, and high-frequency range from $1.25 \mathrm{kHz}$ to $5 \mathrm{kHz}$. In the $\mathrm{T}$ and $\mathrm{X}$ junctions plates 1 and 3 have the same thickness and same material properties. In the $\mathrm{X}$ junction plates 2 and 4 have the same thickness and material.

Acoubat software [27] which implements the prediction model has been used to make comparisons with field sound insulation measurements on typical concrete buildings in France. The separating walls were $18 \mathrm{~cm}$ thick concrete, the separating floors were $20 \mathrm{~cm}$ thick concrete with a plastic floor covering and the flanking walls of the faades were $15 \mathrm{~cm}$ to $18 \mathrm{~cm}$ thick concrete with a thermal-acoustic lining. Internal walls were lightweight elements built from a paper honeycomb core sandwiched between gypsum boards. In total, 17 configurations were evaluated for airborne sound insulation (4 of which corresponded to horizontal transmission), and 15 configurations for impact sound insulation (3 of which corresponded to horizontal transmission). The measured data for DnT,w was in the range from $53 \mathrm{~dB}$ to $59 \mathrm{~dB}$ with $\mathrm{LnT}, \mathrm{w}$ in the range from $40 \mathrm{~dB}$ to $55 \mathrm{~dB}$; hence the sound insulation is representative of that between dwellings.

For airborne sound insulation, the new $K_{i j}$ relationships alter the flanking paths, particularly those paths involving the faade walls with the thermal-acoustic lining, in the low frequency range. The single-number quantity, DnT,w, was, on average, 
decreased by $0.6 \mathrm{~dB}$ (a maximum decrease of $1 \mathrm{~dB}$ and a minimum decrease of $0 \mathrm{~dB}$ ) whereas DnT,w $+\mathrm{C}$ was, on average, decreased by $1.1 \mathrm{~dB}$ (a maximum decrease of 2 $\mathrm{dB}$ and a minimum decrease of $0 \mathrm{~dB}$ ). These new results tend to be closer to measured values; on average the difference between prediction and measurement was $0.2 \mathrm{~dB}$ when the prediction uses the new $K_{i j}$ relationships and $0.9 \mathrm{~dB}$ for the prediction using the current $K_{i j}$ relationships (based on the European and International Standards) that are implemented in Acoubat.

For impact sound insulation, the new $K_{i j}$ relationships tend to have more effect than with airborne sound insulation, particularly for horizontal transmission where the impact level was modified over the frequency range between $100 \mathrm{~Hz}$ and 3.15 $\mathrm{kHz}$. The single-number quantities $\mathrm{LnT}, \mathrm{w}$ and $\mathrm{LnT}, \mathrm{w}+\mathrm{CI}$ were, on average, increased by $2 \mathrm{~dB}$ (maximum and minimum differences were also $2 \mathrm{~dB}$ ). For vertical impact sound transmission, the new $K_{i j}$ relationships mainly affect the low-frequency range. Compared to the current $K_{i j}$ relationships a difference of $0.7 \mathrm{~dB}$ (on average) was observed between the two prediction methods (with a maximum increase of $2 \mathrm{~dB}$ and minimum change of $0 \mathrm{~dB}$ ). The predicted impact sound insulation obtained with the new $K_{i j}$ relationships was on average $1.1 \mathrm{~dB}(0 \mathrm{~dB}$ for vertical transmission only) higher than the measured data in terms of $\mathrm{LnT}, \mathrm{w}$ and $1.7 \mathrm{~dB}(0.7 \mathrm{~dB}$ for vertical transmission only) higher in terms of $\mathrm{LnT}, \mathrm{w}+\mathrm{CI}$. The average differences between measurements and predictions using the new $K_{i j}$ relationships were lower than those using the current $K_{i j}$ relationships that are implemented in Acoubat: these were 0.3 $\mathrm{dB}(-0.6 \mathrm{~dB}$ for vertical transmission only) and $0.7 \mathrm{~dB}(0 \mathrm{~dB}$ for vertical transmission only) respectively.

A potential issue with the new $K_{i j}$ relationships is that the use of individual regression curves for different frequency ranges could cause steps to occur in the predicted flanking transmission paths between the low- and mid-frequency ranges and/or the mid- and high-frequency ranges. These steps are less likely to be visible in the overall sound insulation because this is determined by the combination of the direct path and up to 12 flanking paths; hence there is a smoothing effect when they are combined. This smoothing can be seen in the example in Fig. 12 which indicates the changes observed for airborne (vertical configuration) and impact (horizontal configuration) sound insulation from one of the typical concrete buildings discussed above. For these junctions, $-0.5<P C<0.5$, and although three different frequency ranges were used there were no unrealistic steps in the overall sound insulation and no changes in the ranking of the flanking transmission paths. However, the worst step that has been identified from the examples calculated in this section is shown in Fig. 13 where the change from the mid- to the high-frequency range causes a decrease of $1.2 \mathrm{~dB}$ when an increase might have been expected of $\approx 0.5 \mathrm{~dB}$. In practice small steps such as this are unlikely to be mistaken for a feature such as a critical frequency or a mass-spring-mass resonance frequency because these can usually be identified from the sound reduction index of individual elements.

An additional 22 building configurations were evaluated for airborne and impact sound insulation with junctions where $|P C|<1.25$. Using the new $K_{i j}$ relationships instead of the current relationships implemented in Acoubat resulted in an average decrease of $0.4 \mathrm{~dB}$ for DnT,w (maximum decrease of $2 \mathrm{~dB}$ and minimum change of 0 $\mathrm{dB}$ ) and $0.7 \mathrm{~dB}$ for DnT,w+C (maximum decrease of $2 \mathrm{~dB}$ and minimum decrease 
of $1 \mathrm{~dB}$ ). The impact sound insulation was increased by $0.4 \mathrm{~dB}$ on average for both $\mathrm{LnT}, \mathrm{w}$ and $\mathrm{LnT}, \mathrm{w}+\mathrm{CI}$ (maximum increase of $2 \mathrm{~dB}$ and a minimum increase of $1 \mathrm{~dB}$ ). For 7 out of the 22 configurations, the ranking of the flanking transmission paths for airborne sound insulation was changed by the new $K_{i j}$ relationships. The main change was an increase in the strength of transmission across the straight section of $\mathrm{T}$ - and $\mathrm{X}$-junctions in the mid- and high-frequency ranges. For the airborne sound

insulation, the new $K_{i j}$ relationships result in an increased step between the mid- and high-frequency ranges (from $1 \mathrm{kHz}$ to $1.25 \mathrm{kHz}$ ) of $\approx 2 \mathrm{~dB}$. However, the decrease in the single-number quantity was, on average, $0.7 \mathrm{~dB}$ (maximum decrease of $1 \mathrm{~dB}$ and a minimum change of $0 \mathrm{~dB}$ ).

\section{Conclusions}

European and International standards for the prediction of airborne and impact sound insulation in buildings currently give empirical relationships to determine frequencyindependent vibration reduction indices for heavyweight junctions of walls and floors. These relate the ratio of mass per unit areas for the walls/floors that form the junction (independent variable) to the vibration reduction index (dependent variable). This paper confirms earlier findings that the ratio of characteristic moment impedances is a more suitable independent variable than the ratio of mass per unit areas. However, it is shown that retaining use of the vibration reduction index as the dependent variable is problematic. This is because it gives a range of values when the ratio of characteristic moment impedances equals unity due to the normalisation based on the critical frequency in the definition of the vibration reduction index. Simulations of vibration transmission using wave theory show that there is a stronger relationship between the ratio of characteristic moment impedances (independent variable) and the transmission loss (dependent variable) from which the vibration reduction index can subsequently be calculated. The assumption of frequency-independent vibration reduction indices also gives rise to errors due to in-plane wave generation at the junction. Hence for L-, T- and X-junctions of heavyweight walls and floors, numerical experiments with FEM, SFEM and wave theory have been used to develop new relationships between these variables for the low-, mid- and high-frequency ranges. By considering FEM and SFEM for typical wall and floor sizes alongside wave theory based on diffuse field assumptions, the regression curves give rise to vibration reduction indices that represent the average result for many similar junctions in buildings ranging from residential housing to large commercial buildings.

These new relationships have been implemented in the prediction model that is described in the standards to calculate the sound insulation. This indicates that they tend to improve the agreement between the measured and predicted airborne and impact sound insulation with a change in the single-number quantity that was at most $4 \mathrm{~dB}$. The use of individual regression curves for different frequency ranges did not cause unrealistic steps to occur in the overall sound insulation between the low- and mid-frequency ranges and/or the mid- and high-frequency ranges. This is because the overall sound insulation is determined by the combination of the direct transmission path and up to 12 flanking transmission paths; hence there is a smoothing effect when 


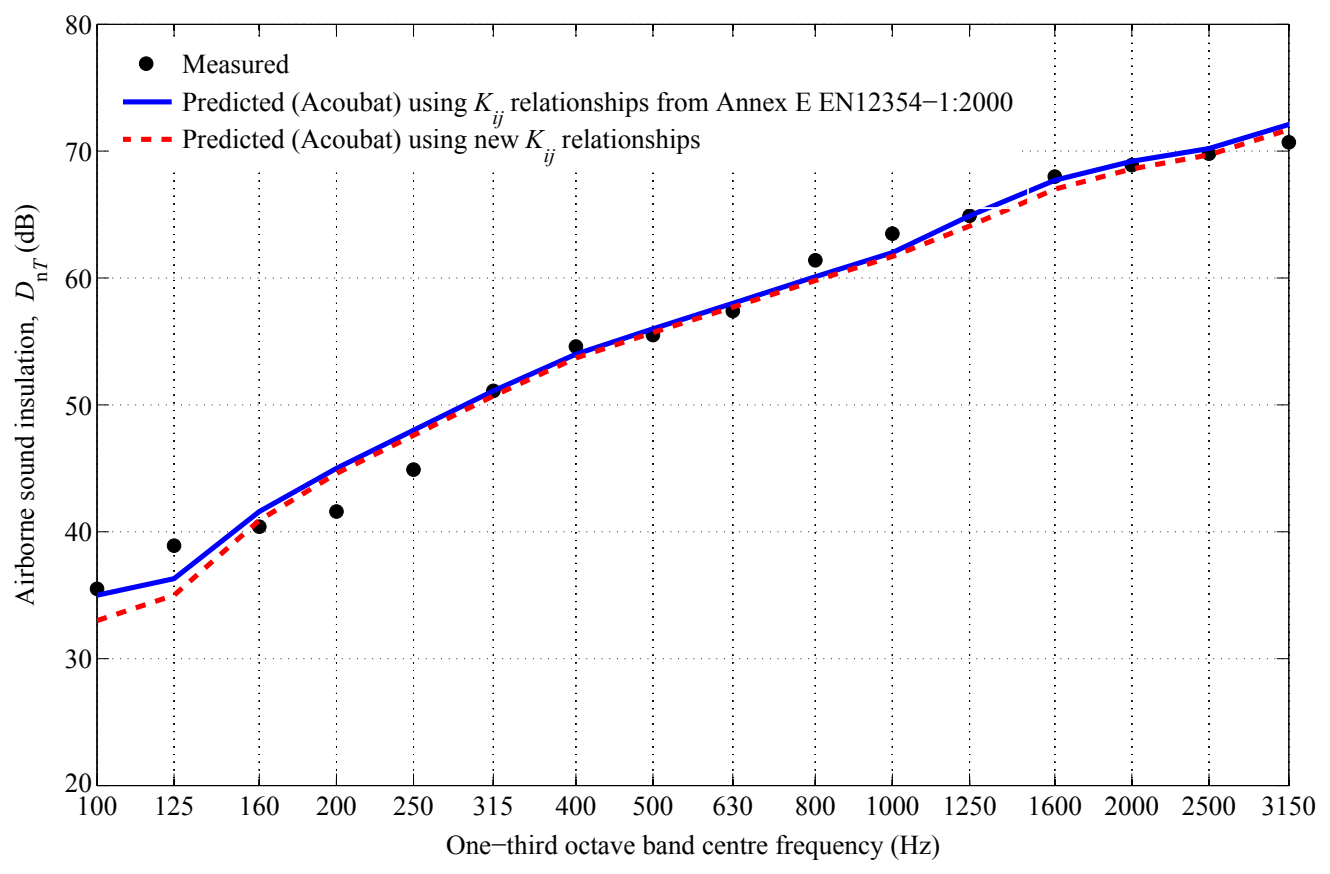

(a)

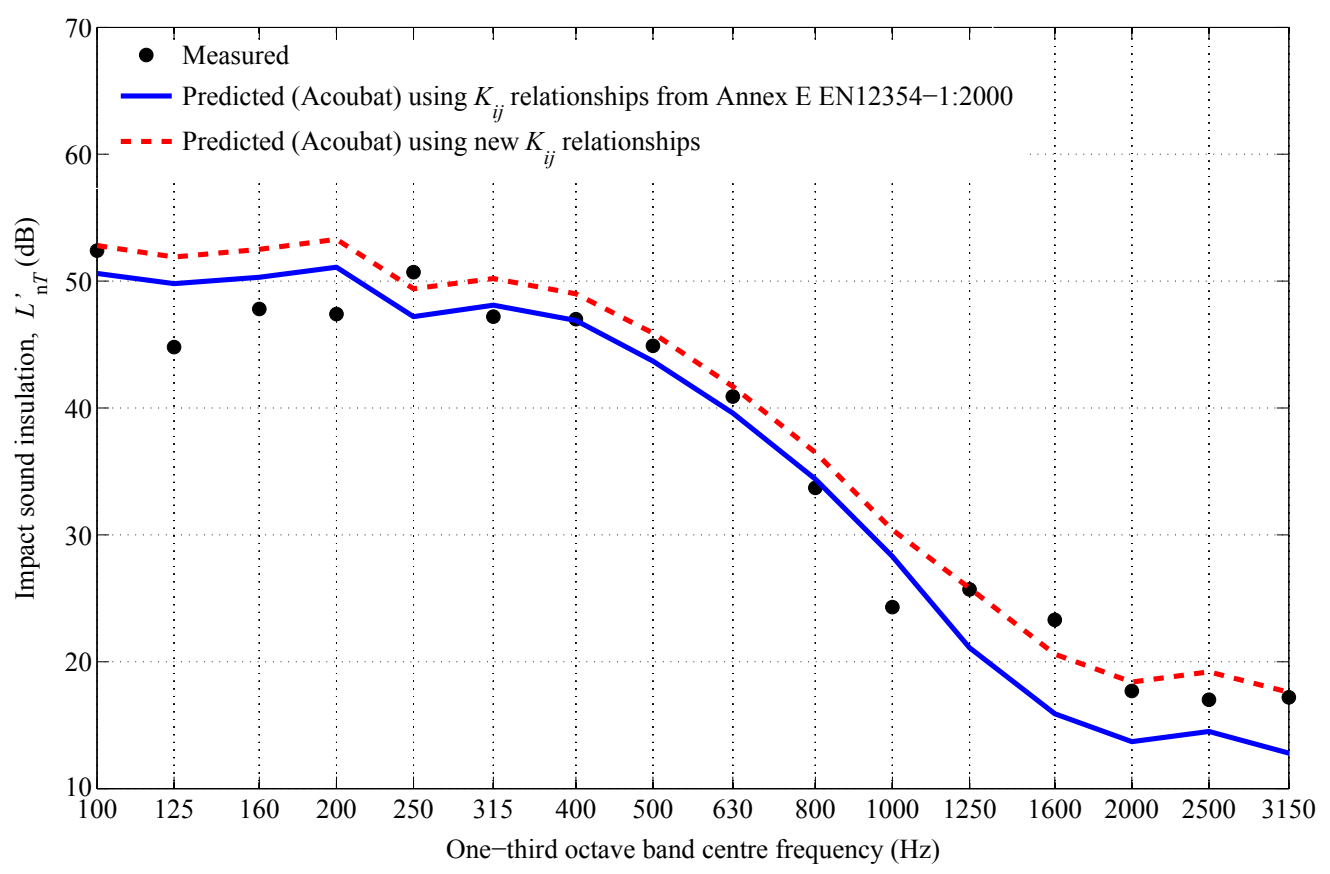

(b)

Figure 12: Comparison of measured and predicted sound insulation using existing and new $K_{i j}$ relationships for a typical concrete building: (a) airborne (vertical configuration) sound insulation, (b) impact (horizontal configuration) sound insulation. 


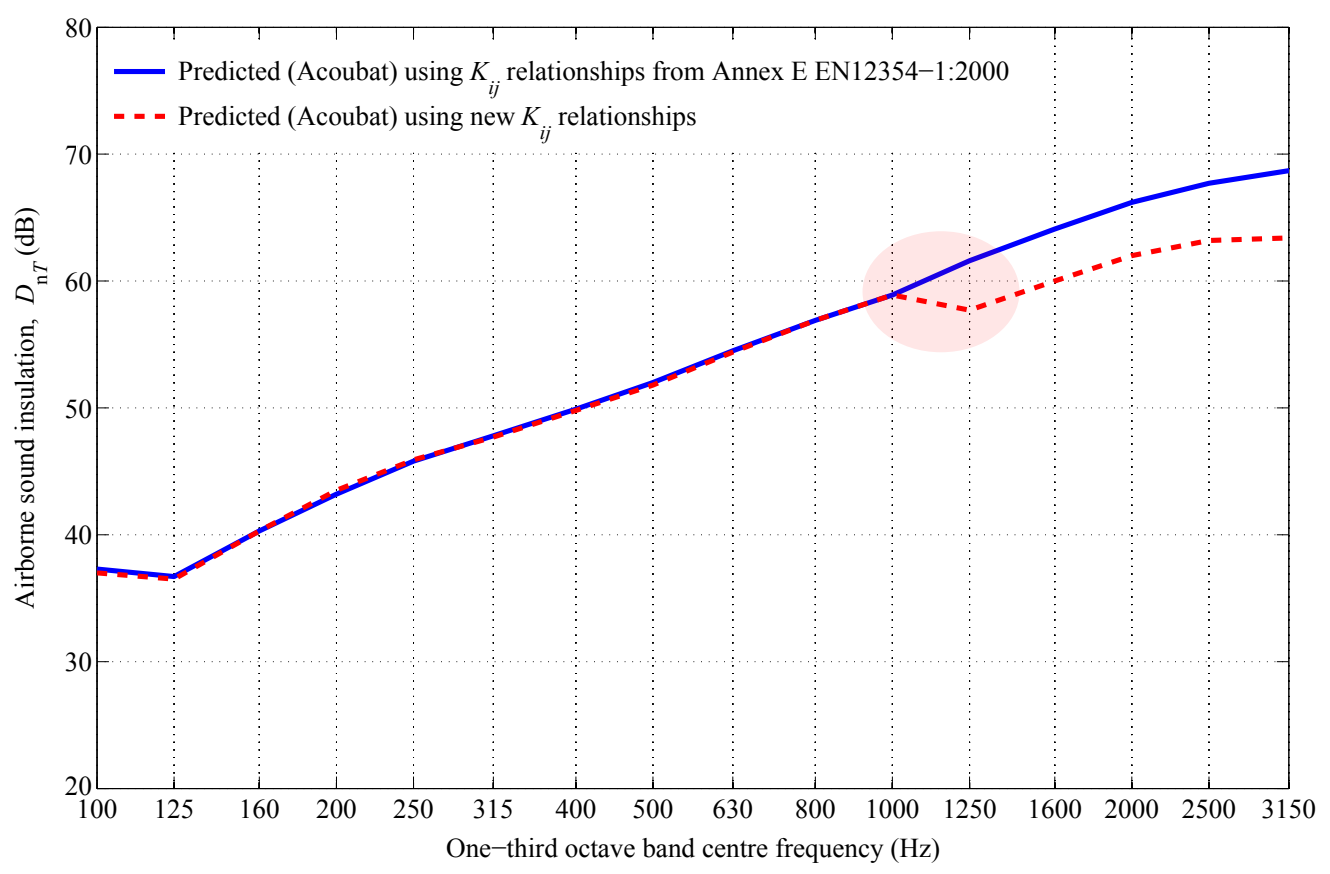

Figure 13: Comparison of predicted sound insulation using existing and new $K_{i j}$ relationships to illustrate the existence of a step from $1 \mathrm{kHz}$ to $1.25 \mathrm{kHz}$.

they are all combined.

These new relationships could be used in the European and International standards to provide clear traceability in the calculation of vibration transmission across heavyweight junctions that links to the use of laboratory measurements on isolated junctions. In addition, FEM and SFEM offers the potential to model significantly more complex junction details than rigidly connected L-, T- and X-junctions in the future, as well as the potential to model heavyweight walls and floors constructed from hollow blocks or slabs. The new relationships will allow future work to assess whether the approach to predicting sound insulation by considering only first-order flanking paths is suitable for a wide range of heavyweight buildings and whether this approach fails in heavyweight buildings with high levels of sound insulation due to the importance of higher order flanking paths.

\section{Acknowledgements}

Carl Hopkins is grateful for financial support from a grant from the Residential Environment Research Program funded by the Ministry of Land, Infrastructure and Transport of the Korean Government (15RERP-B082204-02). Charlotte Crispin is grateful for the financial support from the Federal Public Service Economy of Belgium. Jordi Poblet-Puig from the LaCàN research group is grateful for the sponsorship/funding 
received from Generalitat de Catalunya (Grant number 2014-SGR-1471). The authors are very grateful to Michel Villot (Centre Scientifique et Technique du Bâtiment) and Bart Ingelaere (Belgian Building Research Institute) for their encouragement to carry out this research.

\section{References}

[1] C. Hopkins. Sound insulation. Butterworth-Heinemann, 2012.

[2] Building acoustics estimation of acoustic performance of buildings from the performance of elements. Part 1: Airborne sound insulation between rooms. Part 2: Impact sound insulation between rooms. Standard, International Organization for Standardization, Geneva, CH, 2005.

[3] Building acoustics estimation of acoustic performance of buildings from the performance of elements. Part 1: Airborne sound insulation between rooms. Part 2: Impact sound insulation between rooms. Standard, European Committee for Standardisation, 2000.

[4] E. Gerretsen. Calculation of the sound transmission between dwellings by partitions and flanking structures. Appl. Acoust., 12(6):413-433, 1979.

[5] E. Gerretsen. European developments in prediction models for building acoustics. Appl. Acoust., 2(3):205-214, 1994.

[6] C Hopkins. Determination of vibration reduction indices using wave theory for junctions in heavyweight buildings. Acta Acust. United Acust., 100(6):1056-1066, 2014.

[7] C. Hopkins and M. Robinson. On the evaluation of decay curves to determine structural reverberation times for building elements. Acta Acust. United Acust., 99(2):226-244, 2013.

[8] Acoustics Laboratory measurement of the flanking transmission of airborne and impact sound between adjoining rooms Part 1: Frame document. International Organization for Standardization. Standard, International Organization for Standardization, Geneva, CH, 2006.

[9] C. Hopkins. Measurement of the vibration reduction index, $\mathrm{K}_{i j}$ on free-standing masonry wall constructions. J. Building Acoustics, 6(3-4):235-257, 1999.

[10] Ch. Crispin, B. Ingelaere, M. Van Damme, and D. Wuyts. The vibration reduction index $\mathrm{K}_{i j}$ : Laboratory measurements for rigid junctions and for junctions with flexible interlayers. J. Building Acoustics, 13(2):99-112, 2006.

[11] D.B. Pedersen. Estimation of vibration attenuation through junctions of building structures. Appl. Acoust., 46(3):285-305, 1995. 
[12] R.J.M. Craik. The contribution of long flanking paths to sound transmission in buildings. Appl. Acoust., 62:29-46, 2001.

[13] L. Galbrun. The prediction of airborne sound transmission between two rooms using first-order flanking paths. Appl. Acoust., 69(12):1332-1342, 2008.

[14] H.A. Metzen. Accuracy of cen-prediction models applied to german building situations. Building Acoustics, 6(3):325-340, 1999.

[15] C. Crispin and B. Ingelaere. Review of the empirical formulas for the prediction of the vibration reduction index kij (diva2013/ccr003). Technical report, Belgian Building Research Institute (BBRI), 2013.

[16] L. Cremer, M. Heckl, and E.E. Ungar. Structure-borne sound. Springer-Verlag, 2005.

[17] Ch. Crispin, L. De Geetere, and B. Ingelaere. Extensions of EN 12354 vibration reduction index expressions by means of FEM calculations. In Inter-Noise and Noise-con Congress and Conference Proceedings, volume 249, pages 5859-5868. Institute of Noise Control Engineering, 2014.

[18] J. Poblet-Puig and C. Guigou-Carter. Using spectral finite elements for parametric analysis of the vibration reduction index of heavy junctions oriented to flanking transmissions and EN-12354 prediction method. Appl. Acoust., 99:8-23, 2015 .

[19] C. Hopkins. Revision of international standards on field measurements of airborne, impact and facade sound insulation to form the iso 16283 series. Building and Environment, 92:703-712, 2015.

[20] C. Hopkins. Statistical energy analysis of coupled plate systems with low modal density and low modal overlap. J. Sound Vibr., 251(2):193-214, 2002.

[21] Anon. Actran 15.1 Users Guide. MSC Software. Free Field Technologies SA, April 2015.

[22] C Hopkins. Vibration transmission between coupled plates using finite element methods and statistical energy analysis. Part 1: Comparison of measured and predicted data for masonry walls with and without apertures. Appl. Acoust., 64(10):955-973, 2003.

[23] J.A. Steel and R.J.M. Craik. Statistical energy analysis of structure-borne sound transmission by finite element methods. J. Sound Vibr., 178(4):553-561, 1994.

[24] J. Mahn and J. Pearse. On the uncertainty of the EN12354-1 estimate of the flanking sound reduction index due to the uncertainty of the input data. $J$. Building Acoustics, 16(3):199-231, 2009.

[25] C. Hopkins. Vibration transmission between coupled plates using finite element methods and statistical energy analysis. Part 2: The effect of window apertures in masonry flanking walls. Appl. Acoust., 64(10):975-997, 2003. 
[26] R.J.M. Craik. Damping of building structures. Appl. Acoust., 14(5):347-359, 1981.

[27] CSTB. AcoubatC V\%.0 software. (available from: ftp://ftp.grenoble.cstb.fr/public/acoubat/acoubatsound2014-v'-std/). 